\title{
Decadal and multi-decadal variability of Labrador Sea Water in the north-western North Atlantic Ocean derived from tracer distributions: Heat budget, ventilation, and advection
}

\author{
Hendrik M. van Aken ${ }^{\mathrm{a}, *}$, M. Femke de Jong ${ }^{\mathrm{a}}$, Igor Yashayaev ${ }^{\mathrm{b}}$ \\ a NIOZ Royal Netherlands Institute of Sea Research, Texel, The Netherlands \\ ${ }^{\mathrm{b}}$ Bedford Institute of Oceanography, Darmouth, NS, Canada
}

\section{A R T I C L E I N F O}

\section{Article history:}

Received 10 May 2010

Received in revised form

16 February 2011

Accepted 18 February 2011

Available online 24 February 2011

\section{Keywords:}

Labrador Sea Water

Decadal variability

Tracers

Convection

Ventilation

\begin{abstract}
A B S T R A C T
Time series of profiles of potential temperature, salinity, dissolved oxygen, and planetary potential vorticity at intermediate depths in the Labrador Sea, the Irminger Sea, and the Iceland Basin have been constructed by combining the hydrographic sections crossing the sub-arctic gyre of the North Atlantic Ocean from the coast of Labrador to Europe, occupied nearly annually since 1990, and historic hydrographic data from the preceding years since 1950. The temperature data of the last 60 years mainly reflect a multi-decadal variability, with a characteristic time scale of about 50 years. With the use of a highly simplified heat budget model it was shown that this long-term temperature variability in the Labrador Sea mainly reflects the long-term variation of the net heat flux to the atmosphere. However, the analysis of the data on dissolved oxygen and planetary potential vorticity show that convective ventilation events, during which successive classes of Labrador Sea Water (LSW) are formed, occurring on decadal or shorter time scales. These convective ventilation events have performed the role of vertical mixing in the heat budget model, homogenising the properties of the intermediate layers (e.g. temperature) for significant periods of time. Both the long-term and the near-decadal temperature signals at a pressure of 1500 dbar are connected with successive deep LSW classes, emphasising the leading role of Labrador Sea convection in running the variability of the intermediate depth layers of the North Atlantic. These signals are advected to the neighbouring Irminger Sea and Iceland Basin. Advection time scales, estimated from the 60 year time series, are slightly shorter or of the same order as most earlier estimates, which were mainly based on the feature tracking of the spreading of the $\mathrm{LSW}_{94}$ class formed in the period 1989-1994 in the Labrador Sea.
\end{abstract}

(c) 2011 Elsevier Ltd. All rights reserved.

\section{Introduction}

The Labrador Sea in the north-western North Atlantic Ocean is an area of vigorous warm to cold water conversion (Lazier, 1980; Clarke and Gascard, 1983; Gascard and Clarke, 1983; McCartney and Talley, 1984; Lazier et al., 2002; Straneo, 2006). With this conversion the near-surface water, following Emery and Meincke (1986) named Sub-Arctic Mode Water (SAMW, also named SubPolar Mode Water, McCartney and Talley, 1982; Brambilla and Talley, 2008), is cooled in winter in the central Labrador Sea, and mixes convectively with the underlying water at intermediate levels (Talley and McCartney, 1982). When the winter ends, restratification sets in by the motion of eddies originating from the boundary currents, especially the West Greenland Current. This current brings warm and saline SAMW from the Irminger Sea to the Labrador Sea. During the re-stratification by the eddies, this

\footnotetext{
* Corresponding author. Tel.: +31222 369416; fax: +31222319674.

E-mail address: aken@nioz.nl (H.M. van Aken).
}

water mass, with the overlying fresher surface layer, is brought from the West Greenland Current to the centre of the Labrador Sea, where it rests on top of the cold and homogeneous Labrador Sea Water (LSW) formed in the previous winter (Katsman et al., 2004). The LSW fills the intermediate levels of the Labrador Sea $(\sim 500-2000 \mathrm{~m})$. In the following winter the surface water is cooled again, and convectively mixes into the existing LSW layer. Myers and Donnelly (2008) have estimated formation rates for different density classes LSW from surface buoyancy fluxes and sea surface hydrography over the years 1960-1999. They found a tremendous inter-annual variability of the formation rate. Apart from the classical view of the formation of LSW in the Labrador Sea, several authors supply evidence for local LSW formation in the Irminger Sea (e.g. Pickart et al., 2003; Bacon et al., 2003; Falina et al., 2007; Våge et al., unpublished manuscript). Centurioni and Gould (2004) mention, for the quiet years 1997-2003, a typical thickness of only $400 \mathrm{~m}$ of the surface mixed layer in the Irminger Sea at the end of winter. Profiles of the potential temperature and buoyancy frequency from the cold winter of 2008, published by Våge et al. (2009), suggest that 
convection in the Irminger Sea reaches a factor 1.5-2 less deep than in the Labrador Sea. It is not yet clear how to discriminate between convective SAMW formation in winter in the Irminger Sea and deeper reaching convective LSW formation in the same basin from hydrographic data, mainly collected in the more stratified spring and summer. Mixed layer model simulations for the period 1950-2008 and 11 observation years with moored profiling CTDs in the period 2003-2010 have convinced us that occasionally, in cold winters like 2007-2008, convection in both the western and eastern parts of the Irminger Sea may indeed in some years reach depths of about $1000 \mathrm{~m}$, but that it does not reach $1500 \mathrm{~m}$ in large quantities (de Jong, 2010), where the relatively deep LSW, discussed in this paper, is found. In the period 1990-1997, when the model simulation indicated a mean mixed layer depth in the Labrador Sea of over $1900 \mathrm{~m}$, the mean mixed layer depth in the Irminger Sea never superseded $1000 \mathrm{~m}$, and had a mean value factor 2.7 smaller than in the Labrador Sea. This is attributed to a $33 \%$ weaker mean surface heat flux in the Irminger Sea as well as to a stronger stratification in late summer, when the cooling season starts (de Jong, 2010). Yashayaev et al. (2007a, 2007b) have already shown that the observed development of LSW properties ( $\theta$ and $S$ ) in the Labrador Sea from 1990 onwards is followed by a similar development in the Irminger Sea with a delay of 1-2 years. Apparently the effects of local convection in the Irminger Sea are of minor importance for the temperature and salinity field at the depths where classic LSW is found.

The formation, spreading and decay of water masses and their specific properties are generally studied by means of hydrographic surveys (Tomczak, 1999). The major goal of the global World Ocean Circulation Experiment (WOCE) Hydrographic Program, carried out in the 1990s, was to obtain a representative one-time hydrographic survey of the world oceans. However, attention was also spent on (near-annually) repeated surveys of a number of hydrographic sections to determine the representativeness of such a one-time WOCE survey for the mean state of the ocean, and to estimate the magnitude of seasonal and interannual variability in a variety of seawater properties. One of such repeated survey lines was the AR7 section (grey symbols in Fig. 1) running from Labrador to Greenland (its AR7W part) and from Greenland to the European continental shelf (its AR7E part). The near-annual surveys of this section have not been terminated at the end of WOCE in 1997 but are presently continued as a part of national (Canada's ocean climate monitoring effort run by BIO of DFO, CcSP-CS1 and the Dutch CAMP programme, run by NIOZ) and international ocean observation initiatives (VEINS, THOR). Since this section runs nearly straight through the cyclonic gyres in the central Labrador Sea and the central Irminger Sea, data from this repeat section are useful to study the temporal variability of the formation and spreading of LSW in the northern North Atlantic Ocean. It has appeared that the convective formation of LSW indeed varies from year to year, and that the 8-year long field phase of WOCE (1990-1997) coincided with the generation and spreading of a major cold and fresh LSW class, $\mathrm{LSW}_{94}$. Consequently, its formation, spreading, and decay have been well described recently (Lazier et al., 2002; Yashayaev, 2007; Yashayaev et al., 2007a, 2007b; Falina et al., 2007). By extending the data from the surveys of the AR7 section in the central Labrador Sea with historic oceanographic data from 1960 onwards Yashayaev (2007) and Curry et al. (1998) were able to show that the temperature-salinity characteristics of LSW mainly varied on a multi-decadal time scale ( $\sim 50$ years), with a warm and saline period in the late 1960s and a cold and fresh phase in the mid-1990s. In this paper we repeat that effort, including oxygen profiles, and extend it to other basins, the central Irminger Sea and western Iceland Basin, and to the year 2009.

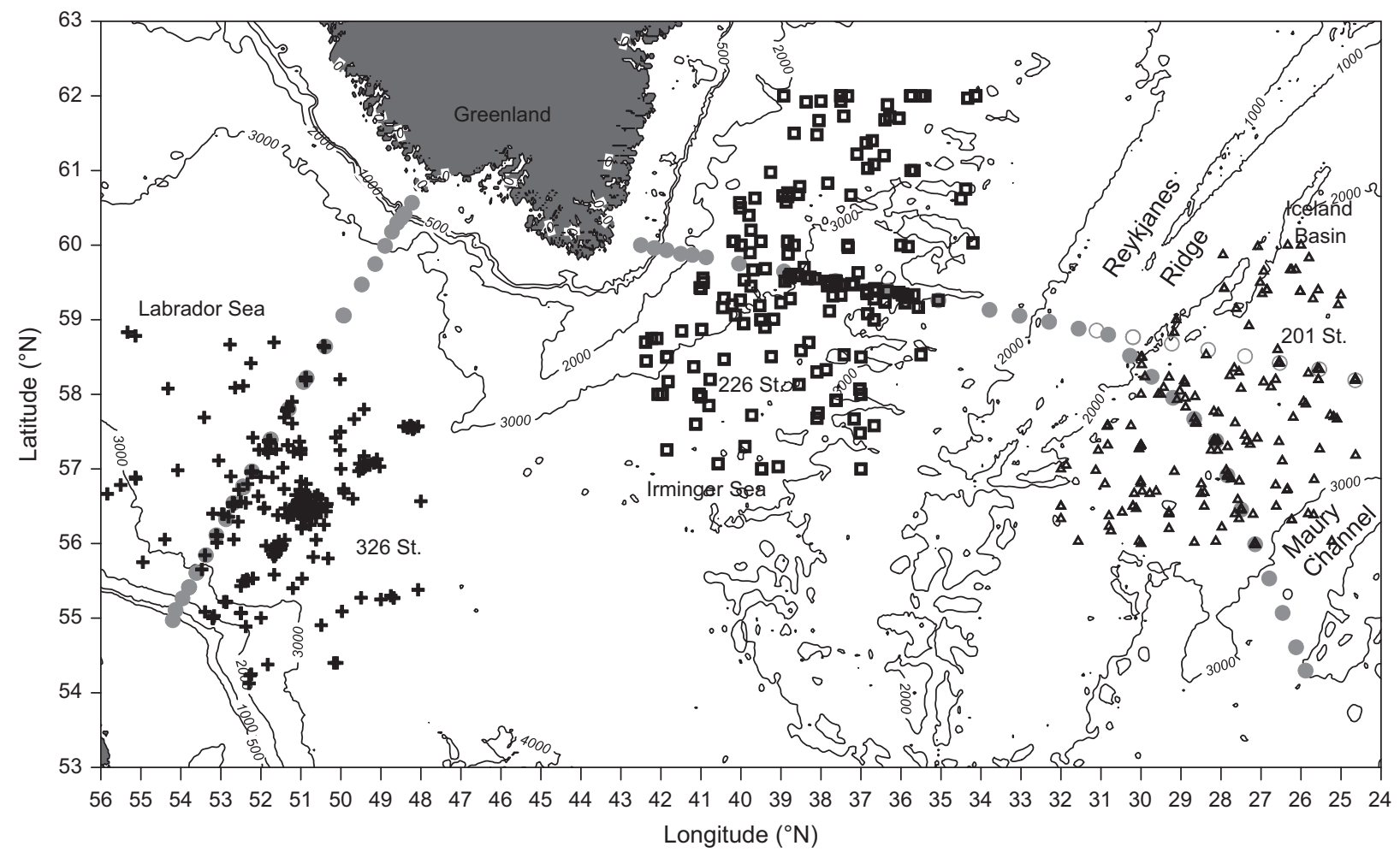

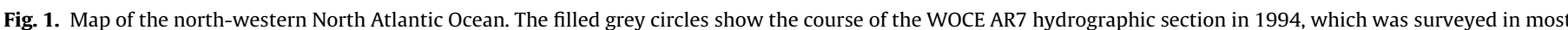

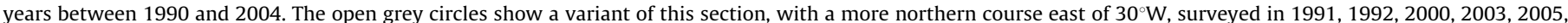

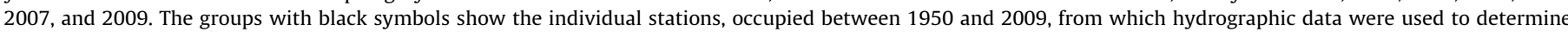

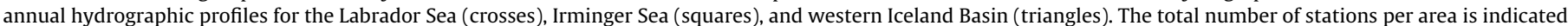
near these station groups. The isobaths in the background represent the water depth in $\mathrm{m}$. 
The newly formed LSW classes spread from the central Labrador Sea to the northeast (the Irminger Sea), to the east (the Iceland Basin), and along the Newfoundland slope to the southeast (Talley and McCartney, 1982; Straneo et al., 2003; Fischer et al., 2004) Entering the deep western boundary current along the American continental slope via such indirect pathways (Bower et al., 2009) LSW contributes to the south flowing North Atlantic Deep Water in the cold branch of the Atlantic meridional overturning circulation (AMOC). Because of the relatively high near-surface salinities outside the Labrador Sea, e.g. in the Irminger Sea and Iceland Basin, LSW can be recognised there by a salinity minimum at intermediate levels. Another approach to the definition of LSW was suggested by Talley and McCartney (1982), who used the vertical homogeneity of the LSW, resulting from the convective formation process, to identify the core of this water mass. The planetary potential vorticity $(P V)$ was used as stability parameter in their study on the spreading of LSW. This $P V$, defined below, is equal to zero in completely mixed water and is linearly proportional to the local stability. Yashayaev et al. (2007a) have proposed a different but related parameter to characterize the core of LSW, the thickness $D$ of $0.01 \mathrm{~kg} / \mathrm{m}^{3}$ density intervals. This parameter is inversely proportional to the planetary potential vorticity, apart from non-linear pressure effects, but less well conserved in case of meridional spreading. Their LSW core is assumed to coincide with the largest volume in a $0.01 \mathrm{~kg} / \mathrm{m}^{3}$ density class, or a minimum in planetary potential vorticity. With such a volumetric definition of the LSW core, Yashayaev et al. (2007a) have determined the properties (potential temperature $\theta$ and salinity $S$ ) of the LSW core in the Labrador Sea for successive years since 1987. It appears that over time the $\theta-S$ properties and the density of the prevailing LSW core have changed. They proposed that successive LSW classes or vintages are formed in one or several successive cold winters. During the formation period the density increases and the potential vorticity decreases, until formation of the particular LSW class ends. After the convective formation period the LSW class is transformed by lateral mixing with the warmer and more saline slope water in the Labrador Sea, until it decays as a result of this mixing process and by advection out of the Labrador Sea (Yashayaev et al., 2007b). In the neighbouring Irminger Sea, this LSW class is introduced there by advection from the Labrador Sea. In the Irminger Sea the transformation and decay progress similarly as in the Labrador Sea. For the observational period 1987-2004, studied by Yashayaev et al. (2007a, 2007b), two different LSW classes have been identified. The $\mathrm{LSW}_{94}$ class has been formed in the cold winters from 1989 until 1994. In 2000 an LSW class, LSW 2000 , was formed in a single winter. In the winter of 2008 a similar formation of a singlewinter LSW class could be observed (Våge et al., 2009; Yashayaev and Loder, 2009). The LSW classes differed in density and other hydrographic characteristics, depending on their formation history.

The planetary potential vorticity, used as a tracer, is via the vorticity budget coupled to the dynamics of the general ocean circulation (Gill, 1982). Other more passive tracers can also be used to follow the formation and spreading of convectively formed water, e.g. chlorofluorocarbons (CFCs) or the tritium-helium ratio. However, such data are relatively scarce and only available in some abundance since the start of WOCE in 1990. Another tracer, already long recognised to be useful for the study of the spreading of LSW, is the concentration of dissolved oxygen (e.g. Dietrich, 1975). With the atmospherically forced convective formation in winter, the LSW is also enriched in dissolved oxygen by air-sea interaction. The upper North Atlantic Deep Water, which originates from LSW, can be traced throughout the Atlantic Ocean by its oxygen maximum. Moreover, this oceanographic parameter has already been measured with reasonable accuracy for a long time, so that it can also be used for research of the ocean ventilation in the past.

As we show below, the temperature variation at intermediate levels in the Labrador Sea is dominated by a time scale of several decades (multi-decadal), and individual ventilation events are hard to recognise from the development of the intermediate temperature. The formation of the $\mathrm{LSW}_{94}$ class has been recognised by a relatively large drop in temperature (Yashayaev, 2007b). However, it can be expected that convective ventilation events will also lower the stability or planetary potential vorticity, and increase the oxygen concentration. In this paper we therefore aim to use the long-term temporal changes of these parameters as tracers, next to the temperature and salinity. With these tracers we study the variability of the north-western North Atlantic Ocean, in particular the formation, transformation, and spreading of the LSW classes in this region. We use the hydrographic data from the AR7 surveys from 1990 until 2009, extended back to 1950 , with historic oceanographic data from international data bases. To keep the analysis simple and focused on large-volume LSW classes, we do not use the volumetrically defined LSW classes (Yashayaev et al., 2007a, 2007b), nor do we describe the time evolution of the LSW by means of the classical core method. Instead we mainly analyse the tracers observed at a pressure level of 1500 dbar to identify those "strong" convective ventilation events that really reach deep. We predominantly discuss these deeper reaching LSW classes, including the $\mathrm{LSW}_{94}$, largely contributing to and in many ways affecting the AMOC. LSW, the most fresh of the source water masses of the cold branch of the global circulation system, seems to be the most sensitive part of the AMOC for disturbances in the freshwater budget of the north-western North Atlantic Ocean. In tests with a simple coupled ocean-atmosphere climate model, it was suggested that LSW formation is the first part of the AMOC that will be shut down in case of large melt water input into the ocean (Rahmstorf, 1995). Monitoring of the LSW properties therefore may show the first changes affecting the strength of the AMOC.

Since the most hydrographic data, used in this study, were collected in the summer half year, the data from the upper 500-750 dbar have been influenced by the re-stratification of the water column, emerging from the warmer and more saline boundary currents in the Labrador and Irminger Sea. Therefore these data are not fit for the study of local formation process of LSW in the Irminger Sea as proposed by Pickart et al. (2003), Bacon et al., (2003), and Falina et al. (2007), nor for the study of the upper LSW, formed in the Labrador Sea by shallow convection near the boundary currents (Kieke et al. 2006; Rhein et al., 2007). Våge et al. (2009) and Yashayaev and Loder (2009) have shown that profiling floats make a view of the deep convection process possible that cannot be achieved by the use of our or similar data sets. However, sufficient amounts of profiling float data in our research area are only available for the last 13 years (Centurion and Gould, 2004; Yashayaev and Loder, 2009).

\section{Data}

For this study we have used the high-quality hydrographic data (temperature, salinity, and oxygen), collected during nearannual surveys of the AR7 hydrographic section since 1990 (http://cchdo.ucsd.edu/), as well as historic data for the preWOCE period from 1950 until 1989, derived from other data bases (black symbols in Fig. 1). For the central Labrador Sea temperature and salinity profiles are available for all years. In the Irminger Sea such profiles are available for 56 out of 60 years, only data for the years 1985-1987 and 1989 are archived. The data availability is less favourable for the Iceland Basin, there 13 years out of the last 52 are missing in the data bases. Data from the AR7 section were also used by Yashayaev et al. (2007a, 2007b) for the description of LSW classes, formed in the 1987-2006 period, and their spreading, transformation, and decay. With hydrographic data from the former WOCE section we have 
determined annual hydrographic profiles $\left(\theta, S, O_{2}, P V\right)$, representative for successive years, for the LSW formation area in the central Labrador Sea, as well as for the central Irminger Sea and the western Iceland Basin. This has been performed by means of robust averaging in density space, as introduced by Yashayaev (2007). The potential density anomaly, relative to a reference pressure of $1500 \mathrm{dbar}, \gamma_{1.5}$, has been derived from the temperature and salinity profiles and is used as density parameter. Similar data sets of only temperature and salinity profiles were constructed by Yashayaev (2007) and Curry et al. (1998) for the Labrador Sea.

Part of the lateral gradients in the ocean basins, especially before 1990 , may be aliased in part into the temporal domain, because of the spreading of observational locations, as shown in Fig. 1. In this study we assume that the effects of this aliasing are minor, compared to the large temporal changes in hydrographic properties. The results of our data processing, especially for temperature and salinity, where a multi-decadal variability appears to be dominant, indicate no considerable high frequency noise that can be attributed to a dominant influence of the aliasing of spatial gradients to the time domain; so this effect indeed seems to be minor.

The intermediate water masses in the WOCE period were strongly dominated by the formation, advection, and decay of the $\mathrm{LSW}_{94}$ class. To document the other LSW formation events we have extended the AR7 data by using data from historic hydrographic stations between 1950 and 1989 from the NOAA World Ocean Data Base (www.nodc.noaa.gov) and some additional data from the ICES oceanographic data base (www.ices.dk). From the Iceland Basin reasonable data coverage by historical data was only available from 1958 onwards. These historical hydrographic stations are indicated by black symbols in Fig. 1. Most of these stations are located within a narrow area at a limited distance from the present AR7 section, but for some years before 1990 we had to use data at a larger distance from this section. The use of annual hydrographic profiles, before 1990 based on observations over a relatively wide region, implicitly assumes that in each basin the lateral property gradients are relatively small. Therefore care was taken by a subjective judgement that stations from the warm and saline boundary currents at intermediate depths in the basins were not included in the calculation of the annual profiles, and that the individual profiles were consistent with the other profiles from the same year, the previous year, and the following year. If not, individual suspect profiles were rejected. This procedure, although subjective, has in our view led to a consistent set of characteristic annual profiles. It is not possible to develop a complete statistical model for the accuracy of the resulting annual profiles, since it is influenced by random and systematic measurement errors, seasonal bias, the influence of natural spatial and temporal variability, the number of individual profiles available to calculate the annual profile, and the number of samples per profile. However to get a subjective impression of the internal consistency of an annual profile one can use the standard deviation, derived from the difference between original sample data and mean profile data. One has to note that, since samples generally do not coincide with the grid points of the vertical interpolation grid, also some vertical spatial variability will contribute to the standard deviation. An analysis of a representative subset of years resulted in typical standard deviations of $0.07{ }^{\circ} \mathrm{C}, 0.014$, and $2.3 \mu \mathrm{mol} / \mathrm{kg}$, respectively, for temperature, salinity, and dissolved oxygen below 1000 dbar. Given an average of about 5.5 stations per year, these standard deviations suggest an accuracy of the annual values of $0.03{ }^{\circ} \mathrm{C}, 0.006$, and $1.0 \mu \mathrm{mol} / \mathrm{kg}$ (standard errors). As stated before, this is only an impressionistic and rough estimate of the reliability of the individual data points, not firmly based on a statistical error model.

Most of the hydrographic data from the pre-WOCE, WOCE, and post-WOCE periods were obtained in late spring, summer, and early fall. They are therefore potentially biased to the warmer and re-stratified part of the year, and will not accurately reflect the late winter situation in the upper parts of the ocean, when convective homogenisation is at its maximum. However, they are expected to present the inter-annual change of the LSW found at deeper levels.

The planetary potential vorticity, $P V$, defined by

$P V=-\left.\frac{f}{\rho} \frac{\partial \rho}{\partial z}\right|_{a d}$

is a measure of stability of the water column. Here $f$ is the Coriolis parameter, while $\rho$ is the water density, $z$ is the vertical coordinate, and the derivative is applied adiabatically. Convectively formed near-homogeneous water types are characterised by low values of $P V$. Talley and McCartney (1982) have shown that $P V$ is an excellent parameter to trace the spreading of the convectively formed LSW through the North Atlantic Ocean. Therefore we have computed annual profiles of $P V$ from the annual profiles of temperature and salinity.

Additional to the hydrographic data, we have computed estimates of the atmospheric forcing of water mass formation and circulation in the north-western North Atlantic: the annual mean surface heat loss as well as the curl of the wind stress in the central Labrador Sea from 1950 until 2009, based on the NCEP/NCAR reanalysis by the NOAA-CIRES Climate Diagnostics Centre (Kistler et al., 2001, www.cdc.noaa.gov). This data set has been chosen since the NCEP/NCAR reanalysis is available over the whole research period, in contrast with competing flux data sets. According to Renfrew et al. (2002) the NCEP/NCAR turbulent fluxes from the Labrador Sea are comparatively less favourable with direct flux observations than the results from the ERA-40 re-analysis (Uppala and al., 2005), available from 1957 until 2003. A comparison of these data sets gives net annual mean ERA heat fluxes from the central Labrador Sea to the overlying atmosphere with an amplitude, a factor 4.1 smaller than those obtained from NCEP/NCAR. Below in this paper we introduce a heat balance model that clearly shows that the smaller annual mean ERA heat fluxes cannot force decadal temperature variations in the Labrador Sea with a magnitude as observed. The OAFlux annual mean net flux data (Yu and Weller, 2007) from the Labrador Sea have amplitudes only $25 \%$ smaller than those of NCEP/NCAR, but cover only the period 1985-2007.

For the two-dimensional interpolations on a regular grid, performed for this paper, generally a linear Kriging technique has been used. Kriging belongs to the family of optimal linear estimation algorithms, used in geostatistics, which predicts unknown values at grid points from data, observed at other known locations. The predictor is a linearised weighted combination of observational values, which minimises the error of predicted values in some statistical sense (Stein, 1999).

\section{The general hydrographic and tracer structure in the north- western and north-western North Atlantic Ocean}

Distributions of tracers can be used to illustrate the spatial water mass structure in the research area: sections of potential temperature, salinity, dissolved oxygen and silicate, CFC-11, and planetary potential vorticity show an example of the hydrographic structure of the north-western North Atlantic Ocean (Fig. 2). These sections are based on the hydrographic surveys of the Labrador Sea part of the AR7 section (AR7W) by CSS Hudson (18HU94008_1), and of the part of the section east of Greenland (AR7E) by RV Meteor (06MT30_3), carried out, respectively, in June and December 1994. Some Meteor data from 1994 are also available for the AR7W section, but that western section is not completely covered in the Meteor survey. All data were inspected by eye, and evident outliers were removed. The oxygen and CFC-11 data of the Hudson cruise have been adjusted to 
those of the Meteor cruise by comparison of data from 15 nearcoinciding stations in the Labrador Sea, following recommendations from the CARINA project (Tanhua et al., 2010). The CFC-11 concentrations of the Hudson cruise had to be multiplied with a factor $1.35( \pm 0.11)$, definitely higher than the factor of 1.05 , recommended by Tanhua et al. (2010) and Steinfeldt et al. (2010). The correction factor for the oxygen data from the Hudson cruise had to be reduced with $3 \%( \pm 1 \%)$, a larger correction than the $1 \%$ reduction, recommended by Stenardo et al. (2009). Parts of the AR7 section already have been published by Falina et al. (2007), Yashayaev (2007), Yashayaev et al. (2007a), and AzetsuScott et al. (2003). The maximum extent of the LSW $_{94}$ class in the Labrador Sea was observed in 1994 (Yashayaev et al., 2007a, 2007b). Although the intermediate waters in the Irminger Sea had been cooling since the early 1970s (Yashayaev, 2007), the LSW $_{94}$ class had not yet fully reached the Irminger Sea east of Greenland in 1994, and certainly not the Iceland Basin east of the Reykjanes Ridge
(Yashayaev et al., 2007a). The water mass at intermediate levels in the Labrador Sea was relatively homogenous, with a potential temperature below $2.75{ }^{\circ} \mathrm{C}$ and salinity below 34.85. Dissolved oxygen concentrations were also homogenous at these levels and had risen to above $305 \mu \mathrm{mol} / \mathrm{kg}$ in the Labrador Sea, while the homogeneously distributed silicate concentrations had values between 9 and $10 \mu \mathrm{mol} / \mathrm{kg}$. The high-salinity core of NEADW below the LSW layer showed silicate concentrations above $12 \mu \mathrm{mol} / \mathrm{kg}$, originating from the old near bottom water in the Iceland Basin. Also the CFC-11 concentration was high and more or less distributed evenly at intermediate levels, with values of over $4.5 \mathrm{pmol} / \mathrm{kg}$ on the Labrador Sea, over $4.0 \mathrm{pmol} / \mathrm{kg}$ in the Irminger Sea, and over $2.5 \mathrm{pmol} / \mathrm{kg}$ in the Iceland Basin. The gridded potential vorticity PV showed a minimum below 1000 dbar between $1.0 \times 10^{-12}$ and $1.5 \times 10^{-12} \mathrm{~m}^{-1} \mathrm{~s}^{-1}$ in the Labrador Sea, and between $2.0 \times 10^{-12}$ and $2.5 \times 10^{-12} \mathrm{~m}^{-1} \mathrm{~s}^{-1}$ in the Irminger Sea, and between 10 and $15 \times 10^{-12} \mathrm{~m}^{-1} \mathrm{~s}^{-1}$ in the Iceland Basin. The potential density

a

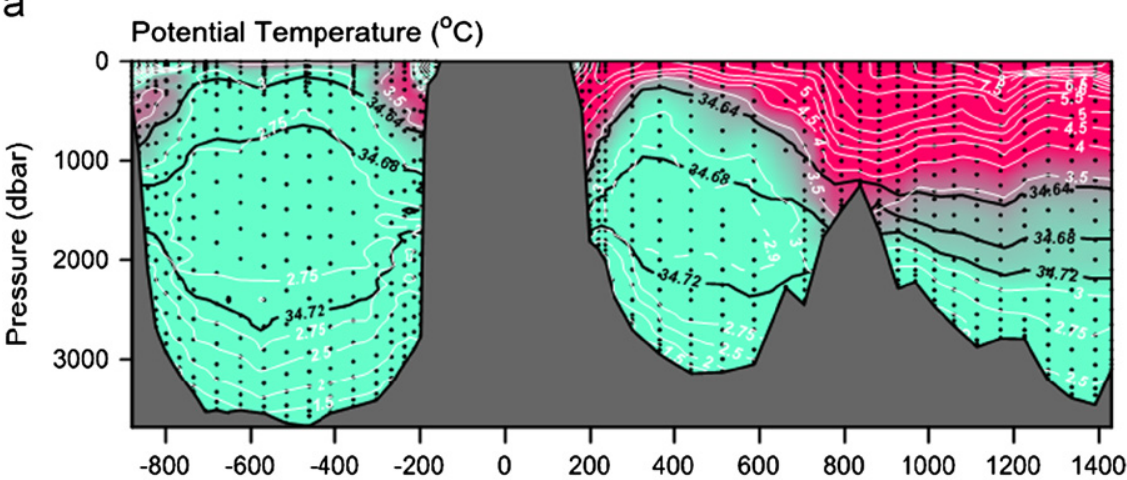

b

Salinity (PSS-78)

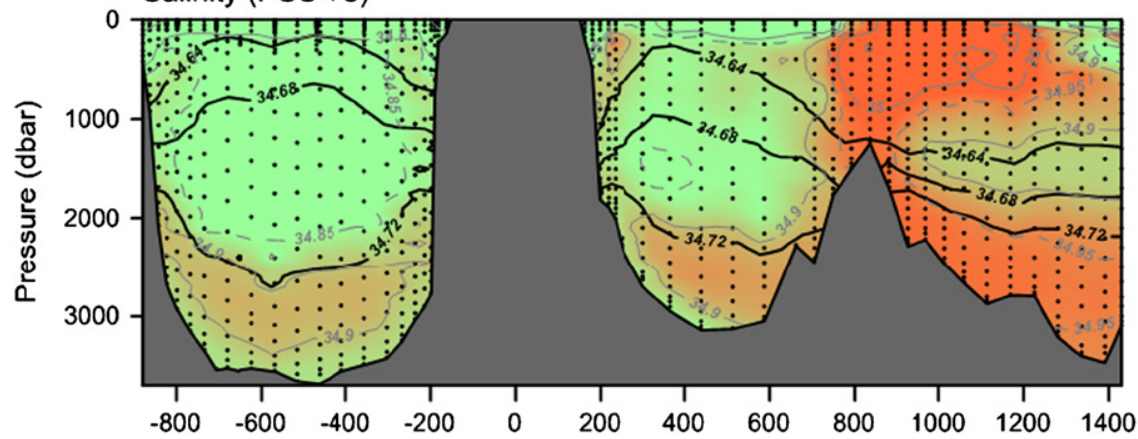

C

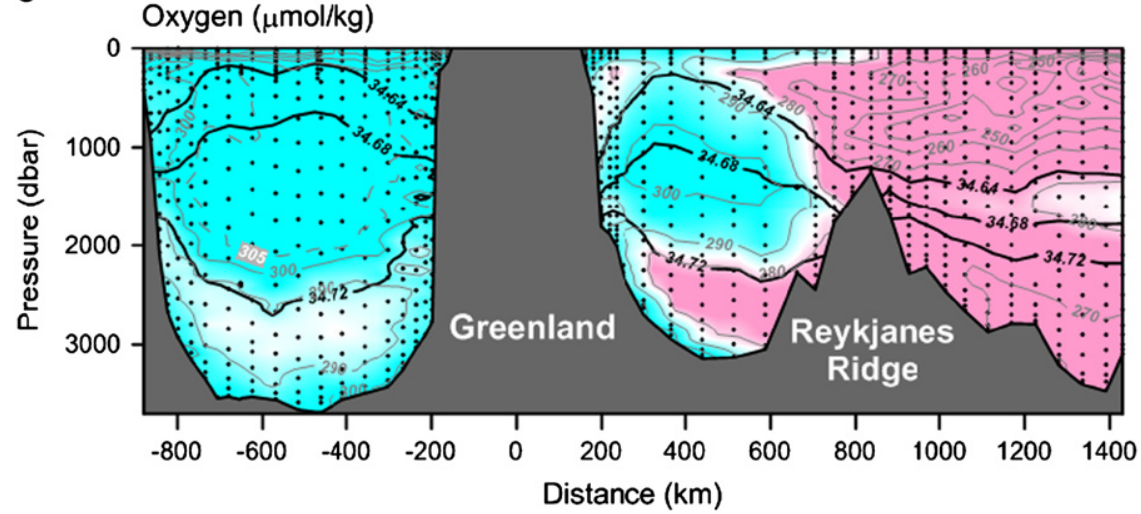

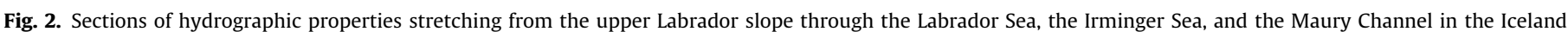

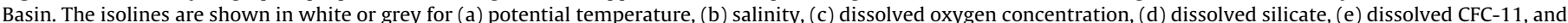

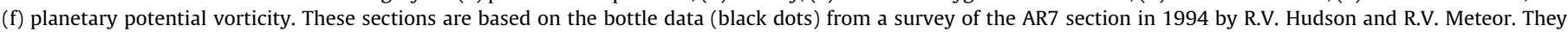

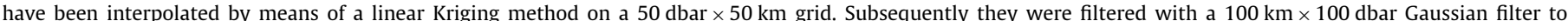
suppress small-scale noise. The black lines show the $\gamma_{1.5}=34.64,34.68$, and $34.72 \mathrm{~kg} / \mathrm{m}^{3}$ isopycnals. 



Fig. 2. (Continued)

anomaly $\gamma_{1.5}$ of the potential vorticity "core" of the homogeneous $\mathrm{LSW}_{94}$ class in the Labrador Sea, derived from these tracer distributions, was about $34.685 \mathrm{~kg} / \mathrm{m}^{3}$.

In the upper 200 dbar above the $\mathrm{LSW}_{94}$ core in the Labrador Sea, shown in Fig. 2, re-stratification after the preceding winter was reflected by a rise of the potential vorticity in the near-surface layer. This re-stratification had raised the temperature and lowered the salinity of the upper ocean. The near-surface oxygen concentration was already high because of the onset of the spring bloom. The nearsurface concentration of dissolved silicate was relatively low, due to a spring bloom of diatoms. The surface concentrations of CFC-11 were high because of recent air-sea interaction. Along the surrounding slopes of the Labrador Sea, a warmer and more saline water mass was observed at the density levels of the LSW core, the Icelandic Slope Water (ISW; van Aken and de Boer, 1995; van Aken and Becker, 1996). This water mass had relatively "aged" tracer properties compared with the LSW core, a lower oxygen concentration, higher silicate values, lower CFC-11 concentrations, and a higher potential vorticity. The ISW at the LSW levels could be followed along its path from the north-eastern Iceland Basin to the
Labrador Sea as a slope bound water mass in the Iceland Basin, the Irminger Sea, and the Labrador Sea (Yashayaev et al., 2007a). Below the LSW core a more saline water type was found, the North East Atlantic Deep Water (NEADW), characterised by higher salinities ( > 34.90), lower oxygen and CFC concentrations, and a higher silicate concentration. This water mass is formed when Iceland Scotland Overflow Water (ISOW) spreads to the western Atlantic Basins through the Charlie-Gibbs Fracture Zone in the Mid-Atlantic Ridge at $\sim 52^{\circ} \mathrm{N}$ (van Aken and Becker, 1996). From there NEADW is brought to the Labrador Sea by the deep cyclonic sub-arctic gyre circulation. It is suggested that the transport (Boessenkool et al. 2007) and properties (Yashayaev and Dickson, 2008) of ISOW and subsequently NEADW are significantly regulated and influenced by the varying formation rates and properties of LSW.

Also in the Irminger Sea a homogeneous water type was present in 1994 at intermediate levels where convectively formed (low PV) LSW is found, although the coldest and densest modification stage of the $\mathrm{LSW}_{94}$ class had not yet fully reached the Irminger Sea in 1994 (Yashayaev et al., 2007a, 2007b). The potential temperature of the LSW was between 2.78 and $2.9{ }^{\circ} \mathrm{C}$, 
and salinities below 34.85 were found in a smaller volume of the LSW body, compared to the Labrador Sea. The oxygen concentration showed a large maximum in the LSW core with values between 300 and $303 \mu \mathrm{mol} / \mathrm{kg}$, on average about $5 \mu \mathrm{mol} / \mathrm{kg}$ lower than in the Labrador Sea. The dissolved silicate had values between 9 and $10 \mu \mathrm{mol} / \mathrm{kg}$, and the CFC-11 concentration showed there a maximum of over $4 \mathrm{pmol} / \mathrm{kg}$, Overall, the LSW in the Irminger Sea was in 1994 warmer, more saline, less oxygenated, and more stable (higher $P V$ ), and with less CFCs than in the Labrador Sea. Most of the tracer distributions from 1994 in the Irminger Sea show an LSW core close to the $\gamma_{1.5}=34.68 \mathrm{~kg} / \mathrm{m}^{3}$ isopycnal. This slightly lower core density compared to the Labrador Sea is indicative for a delay in the arrival of the highdensity $\mathrm{LSW}_{94}$ core in the Irminger Sea. In the Irminger Sea ISW, a more stable warm and saline water mass with relatively low oxygen and CFC concentrations and higher silicate concentrations than the LSW in its centre is also encountered over the surrounding slopes, especially over the western slope of the Reykjanes Ridge. Its temperature, salinity, and oxygen concentration are higher than those of the ISW in the Labrador Sea. NEADW, underlying the LSW core in the Irminger Sea, is also characterised by a higher salinity, higher nutrient concentrations, and lower concentrations of dissolved oxygen and CFCs.

In the less homogeneous Iceland Basin, east of the Reykjanes Ridge, there is less physical space occupied by the LSW core. The upper $1000 \mathrm{dbar}$ is dominated by the presence and input of warm and saline waters arriving with the Irminger Current, which in its turn descends from the North Atlantic Current. These waters are characterised by an underlying oxygen minimum in the stable permanent thermocline, while the bottom layer over the eastern flank of the Reykjanes Ridge contains relatively cold and saline ISOW, while the deep Maury Channel is dominated by fresher, old, low-oxygen, and high-nutrient Lower Deep Water (LDW). LDW is a water mass with Antarctic contributions, hence its lower salinity and high silicate concentration. In between these water masses the low-stability, low-salinity and well oxygenated LSW core is found at a potential density of about $\gamma_{1.5}=34.66 \mathrm{~kg} / \mathrm{m}^{3}$. This lower density of the LSW core in 1994 in the Iceland Basin suggests that the arrival of the high-density LSW $_{94}$ class is there even more delayed than in the Irminger Sea.

\section{Inter-annual and multi-decadal changes in the Labrador Sea}

The time-pressure distributions of potential temperature, salinity, dissolved oxygen and potential vorticity have been constructed for the central Labrador Sea from the annual hydrographic profiles for 60 years from 1950 to/through 2009 (Fig. 3). The oxygen plot only stretches from 1952 to 2007, since for the first and last two years of the record this parameter was missing from the records. Since oxygen data were also missing for 5 consecutive years in the 1980s (1983-1987) that period is blanked in the oxygen distribution. For 1 or 2 year gaps in the record, the Kriging gridding procedure was used to fill these gaps.

The strongest signal in the temperature distribution, shown in Fig. 3, is a long-term quasi-oscillation of temperature between about 500 and 2000 dbar with an apparent period of about 50 years, spanning nearly the entire 60 year observational period. Whether that is really a dominant time scale for the Labrador Sea temperature also for other eras cannot be decided, because of the limited record length. The highest mean potential temperature is observed in 1970, the lowest in 1994. An intermediate temperature minimum is found near 1976 . The early warming period until 1970 , followed by a cooling trend (until 1976) was already noted by Talley and McCartney (1982). The lowest temperature in the record coincides with the maximum extension of the $\mathrm{LSW}_{94}$ class in the Labrador Sea (Yashayaev et al., 2007a, 2007b). However, although a separate colder period can be recognised around 1976, which was already noted by Curry et al. (1998), it is hard to identify other LSW ventilation events from the temperature distribution alone. The salinity distribution between 500 and 2000 dbar (not shown) also contains a large multi-decadal oscillation, nearly in phase with the temperature signal, with the highest intermediate level salinities in 1964 and 1970, and the lowest salinities in the early 1990s. However, here the multi-decadal signal is modified by a relatively strong decadal signal, comparable in amplitude with the multi-decadal salinity variation. It shows additional salinity maxima between 500 and 2000 dbar (not shown) in 1954 and 1983. The temperature maximum of 1976 at intermediate depths coincides with a relative salinity maximum. In the near-surface layer the salinity shows the presence of a thick surface layer of relatively fresher water from 1968 to 1972 and from 1981 to 1985, named Great Salinity Anomalies, which are assumed to have contributed to the suppression of convective activity in that period (Lazier, 1980; Dickson et al., 1988; Straneo, 2006).

The time-pressure distributions of the dissolved oxygen concentration and planetary potential vorticity show relatively much less multi-decadal variability than the potential temperature and salinity; shorter time scales are dominant. However, the lack of oxygen data in the upper $\mathrm{km}$ from the mid-1950s to 1961 has reduced the temporal resolution in that period, compared to the resolution of temperature and salinity. The strongest signals of oxygen and $P V$ are found at a near-decadal frequency, and are more or less in phase for both parameters. The deep reaching LSW $_{94}$ class and shallower LSW 2000 class (Yashayaev, 2007a, b) are clearly visible in both parameters as high oxygen and low potential vorticity events. It is likely that the earlier events before 1990 with the same parameter combination can be also interpreted as LSW formation events.

A plot of the time series of dissolved oxygen and potential vorticity at specific pressure levels $(750,1000,1250$, and 1500 dbar) in the Labrador Sea simplifies the analysis of LSW formation events (Fig. 4). The oxygen time series at all 4 levels as well as the average from 500 to 2000 dbar show a more or less regular alternation of high oxygen peaks and low-oxygen periods. The oxygen peaks are likely ventilation events recurring at a nearly decadal time scale. At deeper levels the mean oxygen concentration is lower (a $3 \mu \mathrm{mol} / \mathrm{kg}$ mean difference between 750 and 1500 dbar), while the characteristic oxygen increase during and after deep ventilation events also changes vertically, from about $10 \mu \mathrm{mol} / \mathrm{kg}$ at $750 \mathrm{dbar}$ to $13 \mu \mathrm{mol} / \mathrm{kg}$ at $1500 \mathrm{dbar}$. The peaks of high oxygen concentration and low potential vorticity more or less coincide with the peaks in thickness of what Kieke et al. (2006) named "classical LSW" $\left(27.74<\gamma_{\theta}<27.80 \mathrm{~kg} / \mathrm{m}^{3}\right)$, described by them since 1948. This is understandable, since in first order the potential vorticity is inversely proportional to the layer thickness.

The time series of the potential vorticity at different levels (Fig. 4b) show slightly more low-stability events, but overall its main structure agrees with the oxygen signal. Low-stability convection events (peaks in Fig. 4b, note the inverted scale) generally coincide with high oxygen ventilation events. In general the low-stability events in the potential vorticity series show a tendency to decay slightly faster than the high oxygen events. This is likely caused by the interaction of the planetary potential vorticity with the local vorticity, as well as with the horizontal component of the vorticity vector, which represents the vertical shear of the currents. Both are found extensively in the baroclinic eddies, originating from the Greenland slope region, which are responsible for the summer re-stratification after the convective mixing in winter (Katsman et al., 2004). The convection events, derived from the potential vorticity series, are recognised at 

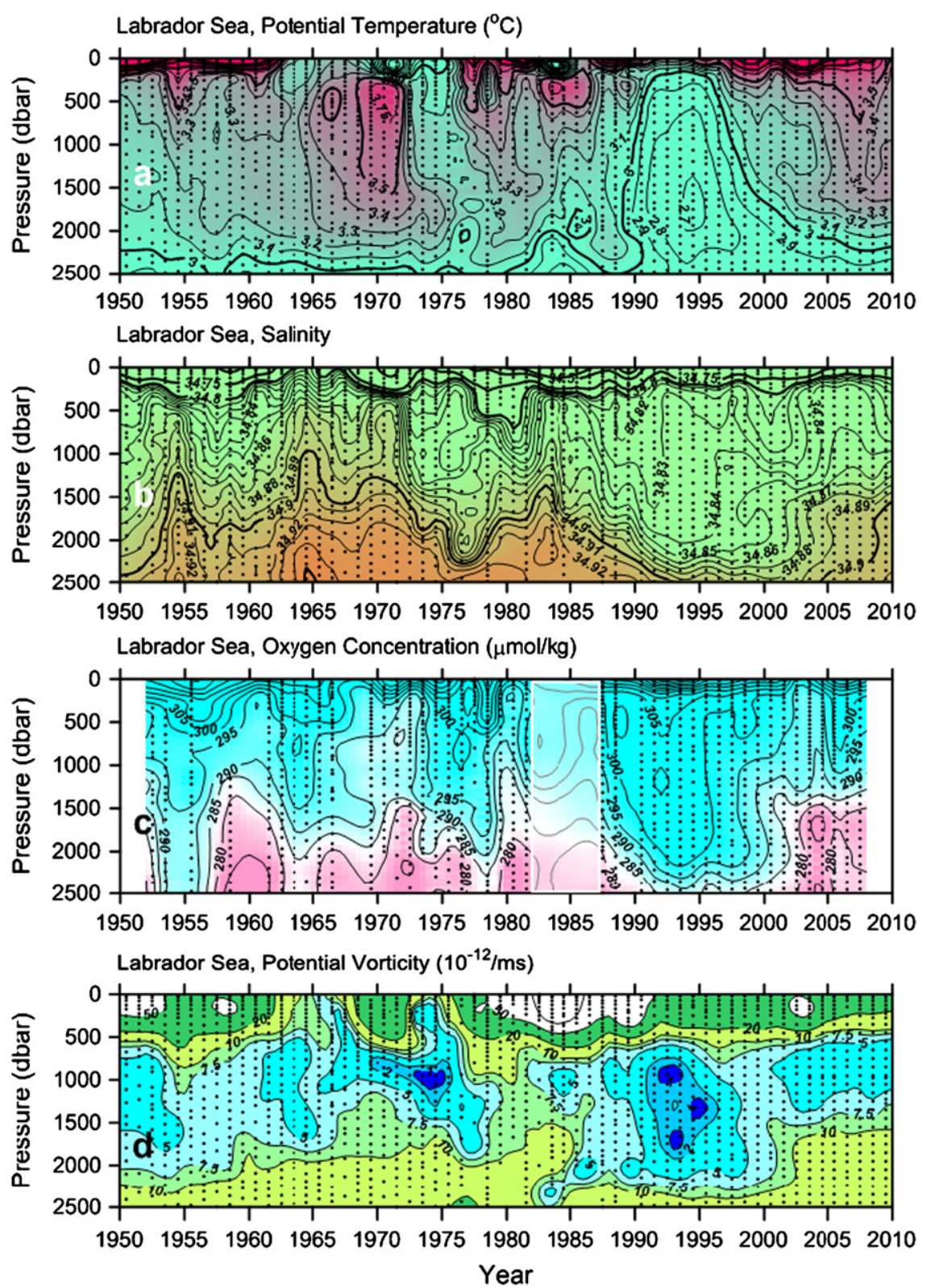

Fig. 3. Time-pressure sections of (a) potential temperature, (b) salinity, (c) dissolved oxygen concentration, and (d) planetary potential vorticity in the central Labrador Sea. The latter parameter was determined with a central derivative from the vertically interpolated temperature and salinity profiles, sub-sampled every 50 dbar, and subsequently filtered with a $2 \times 50$ dbar Bartlett filter. A linear Kriging method was used for the interpolation of the data onto a regular grid.

different depths. While not much happened below 1000 dbar in 1967, the potential vorticity at 750 dbar was reduced with a factor 2 . The relatively shallow low-stability event in the early 1980s did not reach the 1250 dbar isobar, a pressure that was reached by the event in the early 2000s (ULSW or LSW 2000 ) as well as in the winter of 2008.

Comparison of the oxygen and potential vorticity curves for different pressure levels shows that occasionally the signature of convective ventilation events does not reach very deep, e.g. event 4 , where the potential vorticity minimum is not recognised at the 1500 dbar level. This confirms that LSW convective ventilation events do not reach the same deep level at every occurrence, resulting in differing hydrographic properties for successive LSW classes, as proposed by Yashayaev et al. (2007a).

Grey bars have been added to Fig. 4 for events that are observed in both the oxygen and the potential vorticity time series (or appear clearly, with some delay, in the neighbouring Irminger Sea): we will name such events "convective ventilation events". Event 7, the winter convection of 2008 (Våge et al., 2009; Yashayaev and Loder, 2009) is not included in the further discussion, since it had not yet appeared by advection in the Irminger Sea at $1500 \mathrm{dbar}$ during the 2009 survey. During this event a minimum in potential temperature was found in 2008 in the Labrador Sea, centred between 750 and 1350 dbar, likely produced by convective ventilation that reached to about 1650 dbar. In the Irminger Sea in 2008 a small temperature minimum was observed at $1025 \mathrm{dbar}$; here local convection in the 2008 winter did not reach deeper than $1150 \mathrm{dbar}$, certainly not to $1500 \mathrm{dbar}$. As a reference for further discussions we will use data from the 1500 dbar isobar in the Labrador Sea, the Irminger Sea, and the Iceland Basin, focussing mainly on deep reaching convective ventilation events. As Fig. 2 suggests, the isopycnals run close to horizontal at this depth level, so that it represents more or less the same density horizon in all three basins. In the following analysis of the $1500 \mathrm{dbar}$ level we assume that local 
a

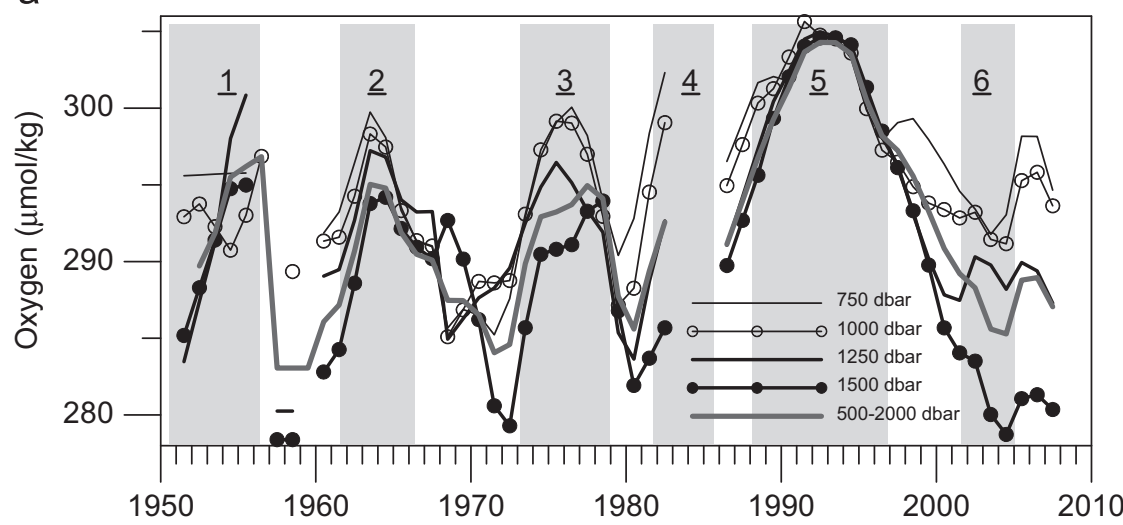

$\mathrm{b}$

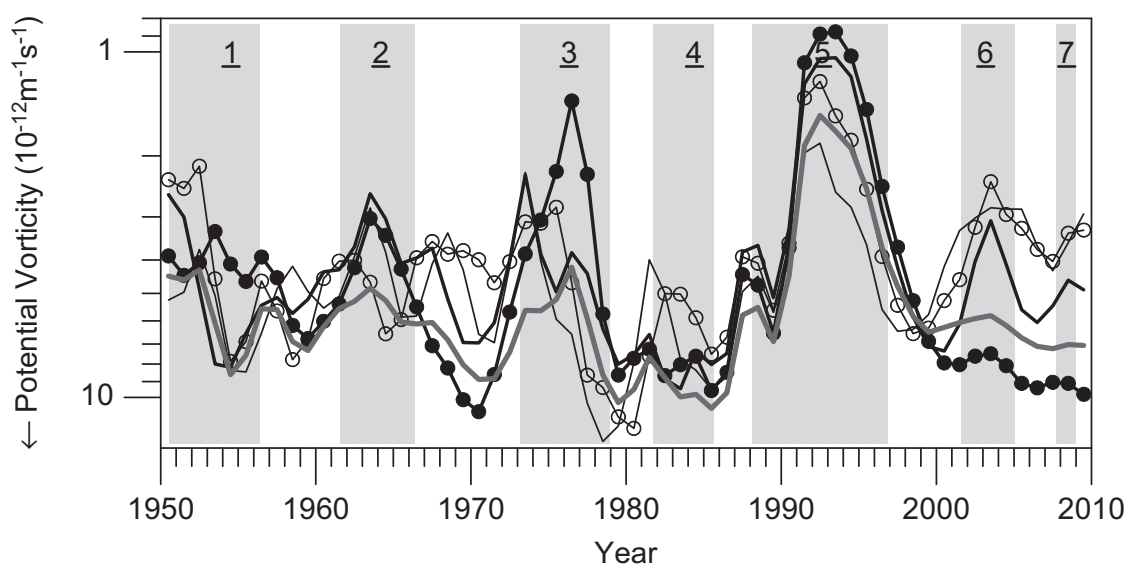

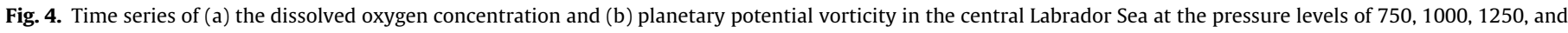

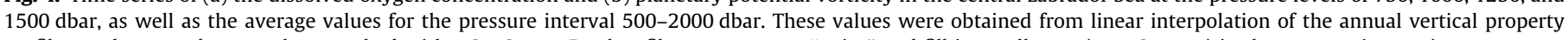
profiles, and were subsequently smoothed with a $2 \times 2$ year Bartlett filter to suppress "noise" and fill in small gaps (max 2 years) in the oxygen time series.

convection in the Irminger Sea does not reach that deep, and that outside of the Labrador Sea hydrographic changes are caused by advection.

First, the combined time series of potential temperature, salinity, oxygen concentration, and planetary vorticity since 1950 at 1500 dbar from the Labrador Sea are presented, together with information on atmospheric forcing (Fig. 5). Sarafanov (2009) has shown that the temperature and salinity of the LSW in the Labrador Sea (150-2000 m) are well correlated with the North Atlantic Oscillation (NAO) index, a measure for the meteorological forcing of the northern North Atlantic Ocean. He attributes this to atmospheric forced changes in the intensity of the deep winter overturning in the Labrador Sea, forced by the surface heat loss, and to changes in the intensity and eastward extension of the sub-arctic gyre forced by changes in the wind field. We have added low-pass filtered parameters (10 year running mean) representing the atmospheric forcing, the annual mean heat flux and the wind stress curl over the central Labrador Sea to Fig. 5. Both forcing factors show a multi-decadal variation with a typical period of about 50 years (comparable with the duration of the presented series), as does the potential temperature in the central Labrador Sea. The annual net heat flux and wind stress curl correlate significantly with the NAO winter index (not shown); $R=0.75$ and 0.77 , respectively. The potential temperature variation shows a large similarity for the period 1962-1995 with the multi-decadal time series of the mean temperature between 1000 and 1500 dbar, presented by Sy et al. (1997), and with the $1500 \mathrm{~m}$ potential temperature series, presented by Curry et al. (1998). When we make a harmonic fit of a 50-year period sine curve with the net heat flux and wind stress curl we find large correlations $(\geq 0.80)$. Apparently, the intermediate temperature in the central Labrador Sea does not follow the rhythm of a succession of convective ventilation events, derived from the oscillating oxygen concentrations and the planetary potential vorticity minima. It has more the character of the longer-term trends in atmospheric forcing of the north-western North Atlantic Ocean (heat flux as well as wind stress curl). The lowest temperature in the 50-year harmonic fit lags 6 years behind the maximum of the harmonic fit of the net heat flux. This shows that the effective thermal memory of the LSW in the Labrador Sea is relatively large, but still small compared to the dominant 50-year time scale. The Labrador Sea is not "well flushed" in 6 years so that several successive years of increased heat loss will lead to a considerable temperature drop and larger convection depths are reached than in a single winter (Lazier et al., 2002). During the 1970s event 3, the downward curving suggests an extra cooling of about $0.3^{\circ} \mathrm{C}$. The cooling during event 5 seems so be quite large, $\sim 0.45{ }^{\circ} \mathrm{C}$ cooling from 1986 until 1994. Events 1, 2, 4, and 6 show less additional cooling, presented by a significant curving of the temperature line. However, these negative decadal temperature dents are definitely smaller than the range of the multi-decadal temperature oscillation, which has a value of over $0.85{ }^{\circ} \mathrm{C}$. This indicates that the multi-decadal change in the Labrador Sea at intermediate depths is more likely to be caused by the long-term atmospheric forcing of the ocean heat budget and circulation than directly by a single convective mixing event. The large thermal memory of the Labrador Sea apparently suppresses temperature variations forced by variations in the net surface heat flux at inter-annual time scales. 
a

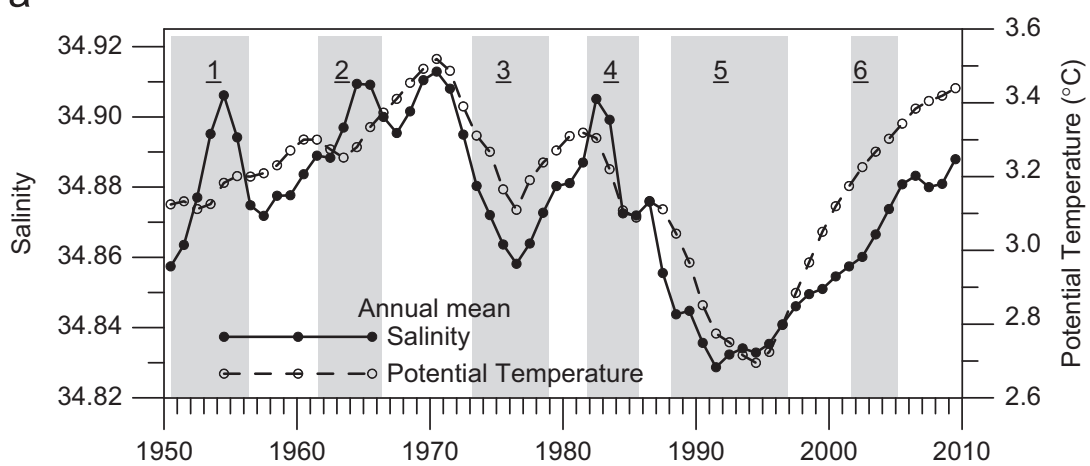

b

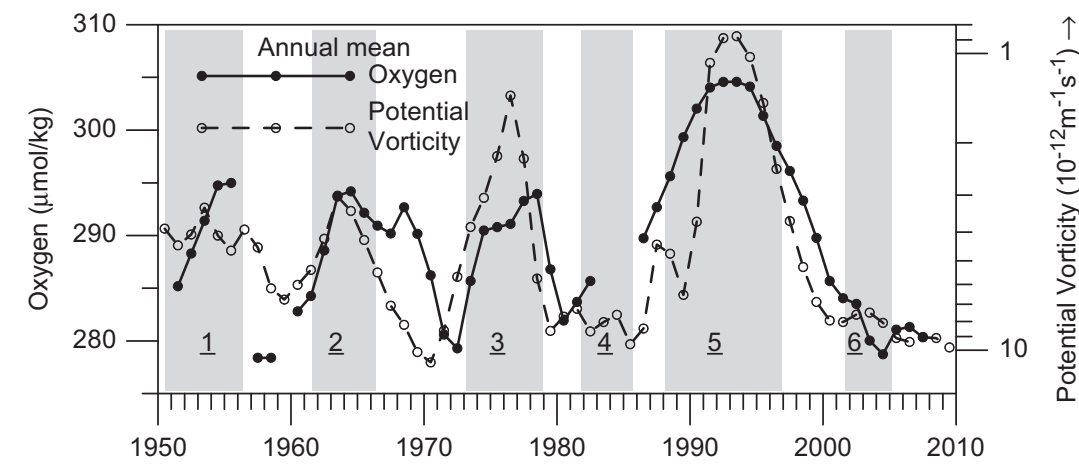

C

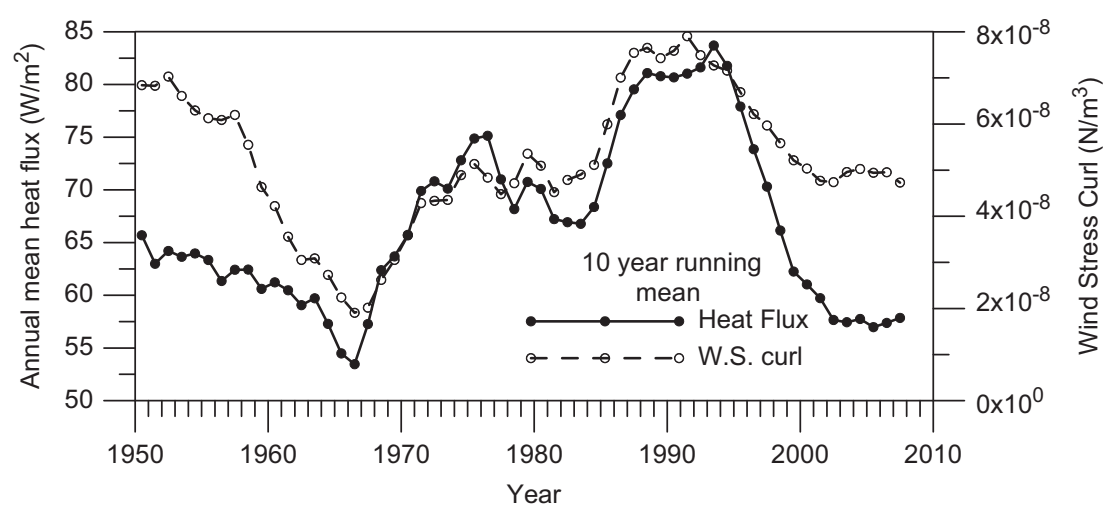

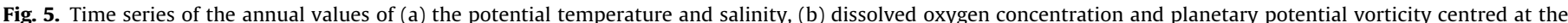

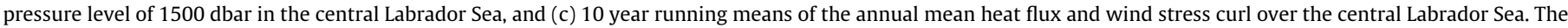

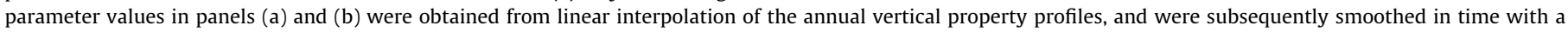
$2 \times 2$ year Bartlett filter to suppress "noise" and fill small gaps (max 2 years) in the oxygen time series.

The stronger convective ventilation events 3 and 5 are accompanied by a decadal cooling event (Fig. 5a and c).

The range of the salinity values is about 0.1 , while the character of the salinity variability shows a mixture of multi-decadal and decadal variations, whereby the multi-decadal variations follow the temperature variations in the Labrador Sea (Fig. 5a). A salinity maximum at 1500 dbar is found around 1970 and a minimum in the 1990s. During the warm first half of the record (1950-1980) the salinity has an average value of 34.874 , while in the colder second half this is reduced to 34.850 . The oxygen concentration and potential vorticity variations at $1500 \mathrm{dbar}$ are more or less in phase and well correlated $(R=-0.70)$.

\section{Inter-annual to multi-decadal changes of LSW in the Irminger Sea and Iceland Basin}

The time-depth distributions for the variation in potential temperature, salinity, oxygen concentration, and potential vorticity since 1950 in the Irminger Sea (Fig. 6) appear to be quite coherent with similar distributions in the Labrador Sea, apart from the stratified near-surface layer (Fig. 4). This suggests that the LSW, formed during convective ventilation events in the Labrador Sea, is advected to the Irminger Sea, north-east of its formation region, However, some influence in the upper $1100 \mathrm{~m}$ due to local convection during cold winters over the north-west Atlantic cannot be ruled out (Våge et al., unpublished manuscript; de Jong, 2010). Varying degrees of re-stratification and summer bias of the observations will also have influence on the variability in the upper $\mathrm{km}$, as shown in Fig. 6. Overall for the whole period 1950-2009, the water column in the Irminger Sea is warmer, more saline, less oxygenised, and more stable than in the Labrador Sea.

The time series of the hydrographic parameters at $1500 \mathrm{dbar}$ in the Irminger Sea (Fig. 8) show many similarities with those at 1500 dbar in the Labrador Sea. Both potential temperature and salinity show a mainly multi-decadal variability with ranges of about $0.67{ }^{\circ} \mathrm{C}$ and 0.10 , respectively, values close to those in the 

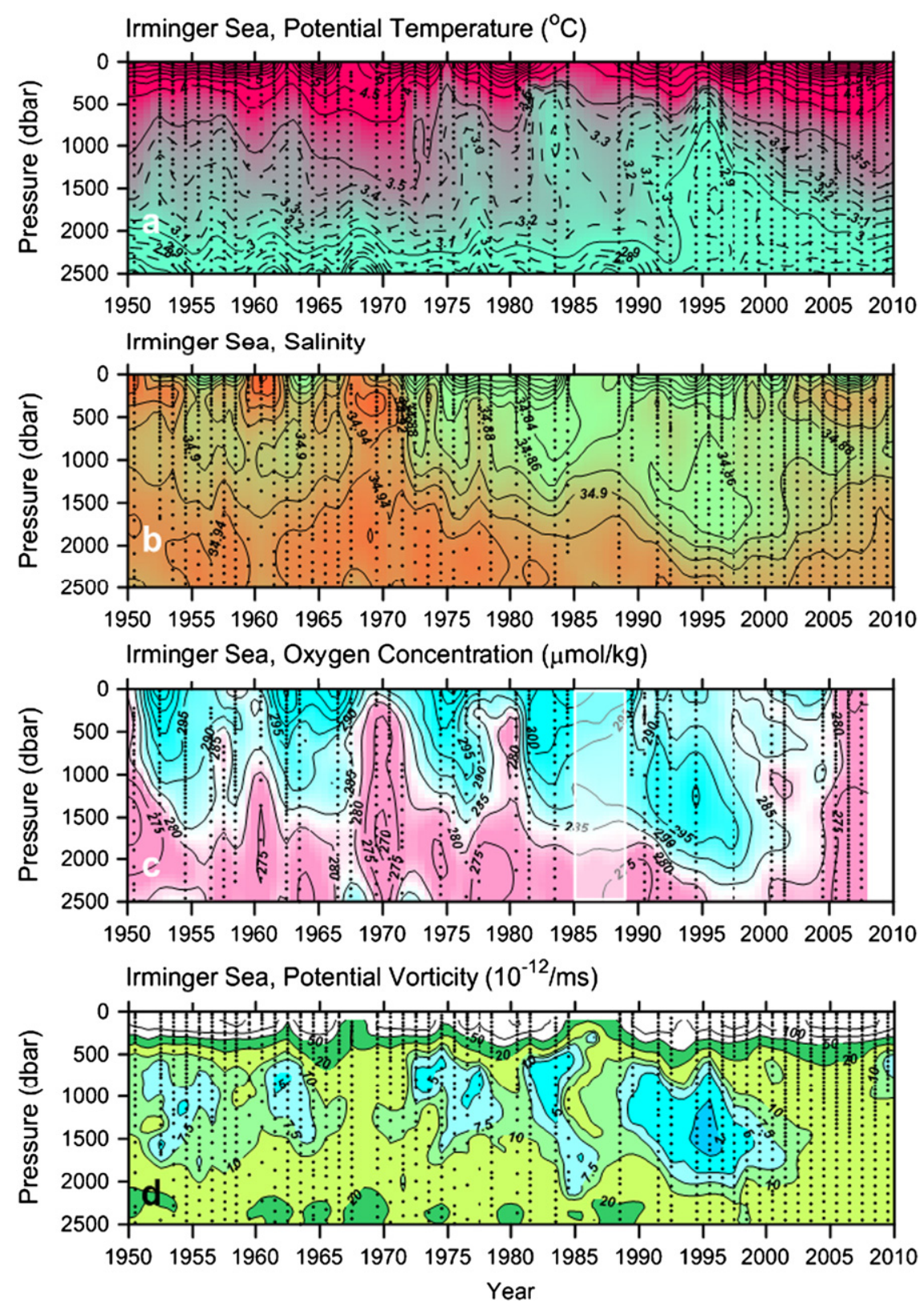

Fig. 6. Time-pressure sections as in Fig. 3, but for the centre of the Irminger Sea gyre.

Labrador Sea. On average the central Irminger Sea is $0.06{ }^{\circ} \mathrm{C}$ warmer and 0.03 more saline at intermediate levels. The oxygen concentration and planetary potential vorticity in the Irminger Sea are dominated by variations at a decadal time scale, similar to the convective ventilation events in the Labrador Sea. If one shifts these events back with a few years (1-3), one can associate the events in the Irminger Sea at 1500 dbar with the deep reaching convection events in the Labrador Sea (the grey bars in Fig. 7), even event 4, which was documented in the Labrador Sea only with a low- $P V$ peak as oxygen data were lacking at that time. The mean values of oxygen and potential vorticity in the Irminger Sea are about $7 \mu \mathrm{mol} / \mathrm{kg}$ lower and $2.7 \times 10^{-12} \mathrm{~m}^{-1} \mathrm{~s}^{-1}$ higher, respectively, than in the Labrador Sea, in agreement with the fact of LSW transformation between the two basins (Yashayaev et al., 2007b). At shallower levels ( $\leq 1000 \mathrm{dbar}$ ) the seasonal re-stratification, encountered during the summer cruises in the Irminger Sea, hinders an insight into the advection of shallower convection events.
The hydrographic time-depth distributions in the Iceland Basin (Fig. 8) are clearly less coherent with the distributions in the Labrador Sea (Fig. 3) than the distributions in the Irminger Sea. The salinity minimum, oxygen maximum, and $P V$ minimum, all three representatives for the LSW core in the Iceland Basin, are centred on an approximate pressure level of about 1500 dbar between the overlying thermocline and the underlying ISOW. The most dominant feature of these parameters at intermediate depths is the oxygen maximum, and salinity minimum from 1995 until 1998, although it remains visible until about 2005. This reminds the arrival of the $\mathrm{LSW}_{94}$ and $\mathrm{LSW}_{2000}$ classes east of the Reykjanes Ridge (Yashayaev, 2007a, 2007b).

Our 1500 dbar time series in the Iceland Basin (Fig. 9) are relatively noisy before 1990 , but still show some coherence with time series from the Labrador Sea. The temperature and salinity time series for the Iceland Basin are much in agreement with those for the Labrador Sea, shifted a few years (validating our assumption about the LSW signal transmission) away from its 
a

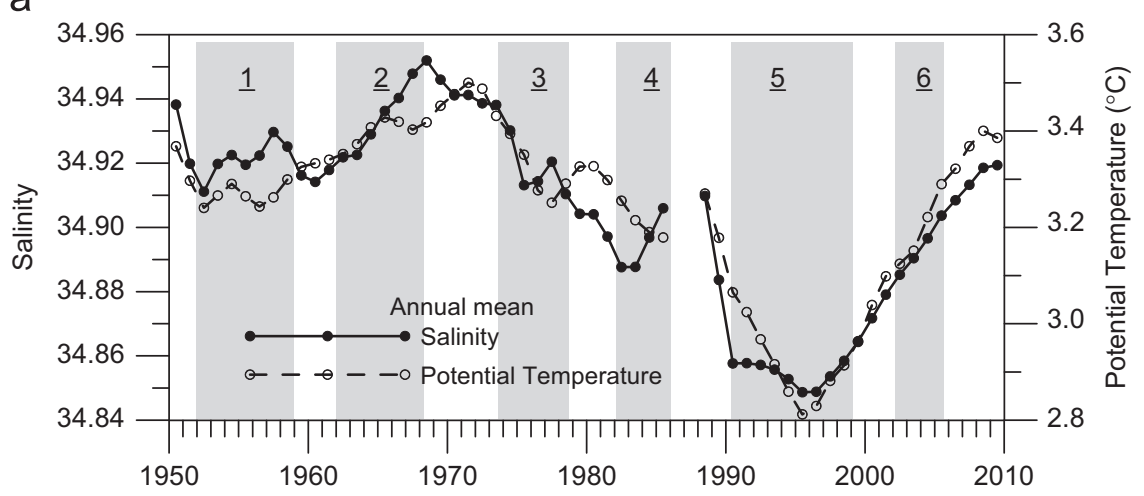

b

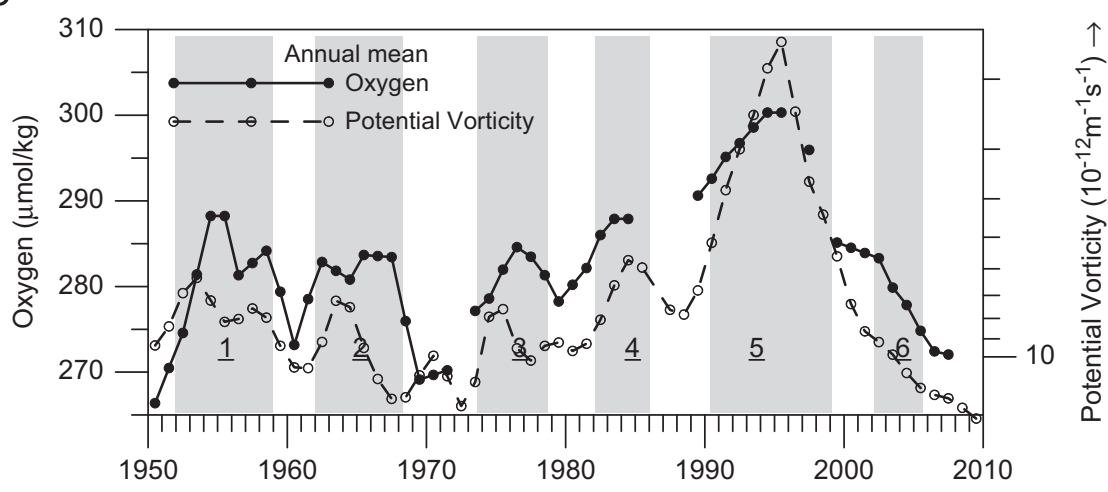

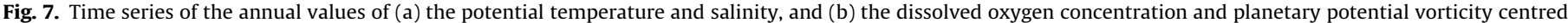

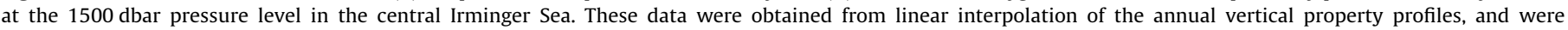
subsequently smoothed with a $2 \times 2$ year Bartlett filter to suppress "noise" and fill small gaps (max 2 years) in the time series.

source. Indeed, the potential temperature and salinity in the Iceland Basin are similarly dominated by a multi-decadal variation, with a maximum at about 1973-1974 and minima in the middle 1990s (1995-1996). The oxygen record shows 3 distinct maxima in the Iceland Basin, about 3 years after the related maxima in the Labrador Sea. However, the phase of the oxygen maximum in the 1990s is uncertain, since from 1993 to 1999 annual oxygen data are available only for 2 years (1994 and 1997). Notwithstanding this uncertainty, the high oxygen events in the Iceland Basin of the 1950s (event 1), around 1980 (3), and the mid-1990s (5), all coincide with relative minima in the planetary potential vorticity, while event 2 is also characterised by a high oxygen value, and event 4 by a low $P V$. At the beginning of the time series in 1958 temperature, salinity, and $P V$ have a relative minimum, while the oxygen concentration has a maximum, reminding of the convective ventilation event 1 in the Labrador Sea. Overall the range of the decadal variation in temperature, salinity, oxygen concentration, and $P V$ is on average about a factor 0.6 ( \pm 0.1 ) smaller in the Iceland Basin, as compared to the Labrador Sea. Apparently some of the hydrographic variability is filtered out when LSW advects from the Labrador Sea eastward across the Reykjanes Ridge.

Previous authors have determined the transit time for the advection of individual newly formed LSW to the Irminger Sea and the Iceland Basin from feature tracking (e.g. Sy et al., 1997; Yashayaev et al., 2007a). How long does the propagation of a temperature or salinity minimum from one basin to the other take, assuming a single location for the LSW formation and a single pathway between the basins? The generalisation of the results of such an analysis requires some additional assumptions, e.g. that the variation in the transit times is small compared to the mean transit time, that the transit time does not depend on the characteristic time scale or intensity of the hydrographic variability, and that long-term hydrographic trends are absent. However, the advection between neighbouring basins may have a range of transit times, depending on the variation of external forcing, while also the varying density structure, related to the LSW distribution itself, may contribute.

Here we use a correlation technique to determine the transit time of LSW from the Labrador Sea to the neighbouring basins, since it will supply a transit time estimate for the whole time series, not for a single feature. Bendat and Piersol (1986) have shown that the expectation values of the cross-correlation function will show a peak around the mean transit time $\tau_{0}$ for nondispersive advection. The actually calculated cross-correlation, as a stochastic estimator, will also contain statistic uncertainties, including an uncertainty in the actual value of $\tau_{0}$. Approximation of the calculated correlation values with a smooth curve, symmetric around some $\tau_{0}$, may reduce this stochastic effect and lead to a more reliable estimate of $\tau_{0}$. Following these techniques we have calculated the time needed for the advection of the convective mixing signal from the Labrador Sea to the Irminger Sea and Iceland Basin from the cross-correlation maximum between the basins of potential temperature, salinity, and oxygen at $1500 \mathrm{~m}$. To prevent a spurious trend to become dominant, the linear trend, derived with a least squares estimate, first was subtracted from the original annual signal. The number of degrees of freedom for each time series was estimated from the integral time scale, estimated from the time-lagged autocorrelation function. The 60 year time series of temperature and salinity each had a typical number of degrees of freedom of 10 and 8, respectively, for the Labrador Sea and the Irminger Sea. The shorter 52 year time series from the Iceland Basin had on average 15 degrees of freedom, possibly because of the relatively large "noise" level, 

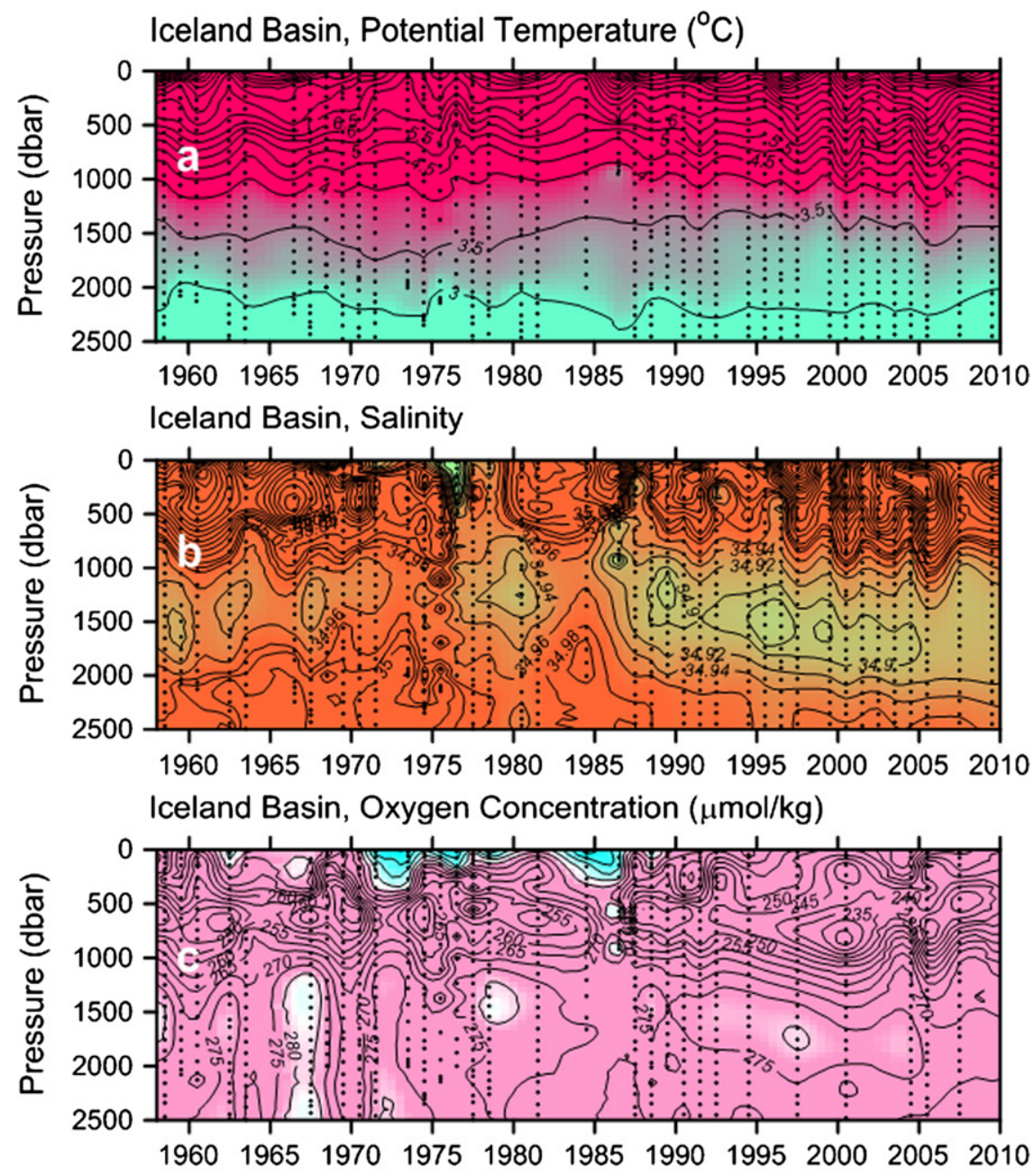

Iceland Basin, Potential Vorticity $\left(10^{-12} / \mathrm{ms}\right)$

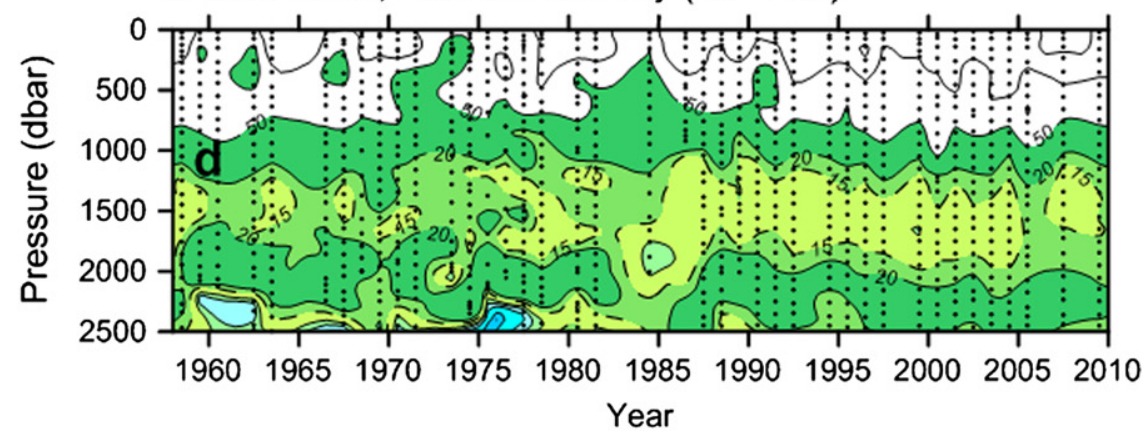

Fig. 8. Time-pressure sections as in Fig. 3, but for the centre of the western Iceland Basin.

induced by other oceanographic processes and/or lack of observations in this basin. The real number of independent data in the multi-parameter time series will be larger since the different parameters may contain different information and different noise. The maximum cross-correlation between Labrador Sea and Irminger Sea was the highest for the potential temperature $(R=0.84)$. The maximum cross-correlations for salinity and oxygen were about 82 and $73 \%$ of the maximum for the potential temperature, respectively. The cross-correlations had a similar asymmetry relative to a zero time lag for all three parameters, the Irminger Sea and Iceland Basin lagging behind the Labrador Sea. Therefore we have averaged the correlations for different parameters (Fig. 10). The magnitudes of the correlation maxima are
$0.72( \pm 0.07)$ and $0.59( \pm 0.06)$ for advection to the Irminger Sea and Iceland Basin, respectively. Given the typical number of degrees of freedom for a single parameter these maximum correlations are (marginally) significant at the $1 \%$ level. For the advection of the ventilation signal from the central Labrador Sea to the central Irminger Sea the maximum cross-correlation was found with a time lag of 2 years, whereas the asymmetry of the correlation function, determined with a parabolic fit to the positive correlation data points (the smooth curve, mentioned above), suggests a smaller advection time, $\tau_{0} \approx 1$ year (thick line in Fig. 10a). The advection of the signal from the central Labrador Sea to the western Iceland Basin took longer, about 1.5 (asymmetry of the crosscorrelation from the parabolic fit) to 3 years (maximum of the 
a

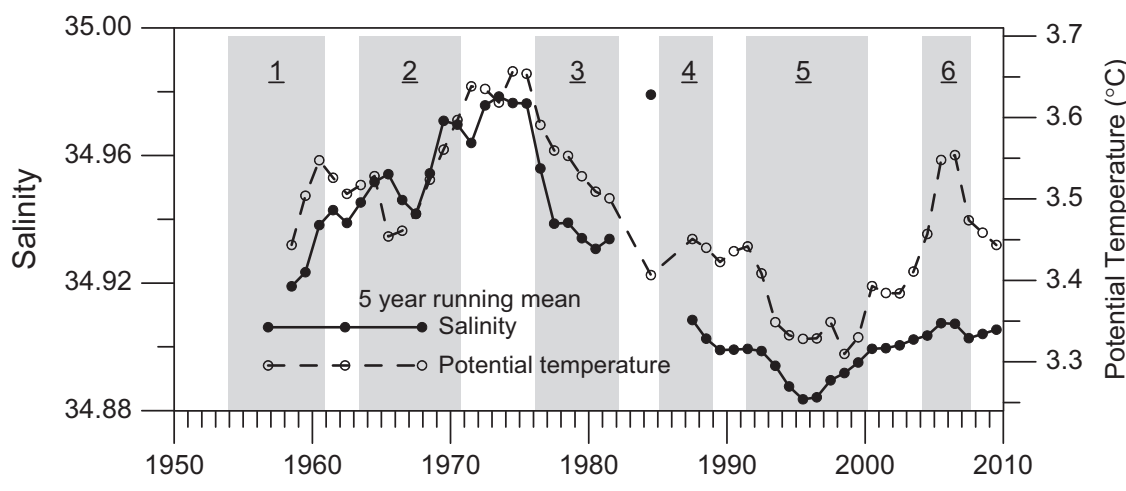

b

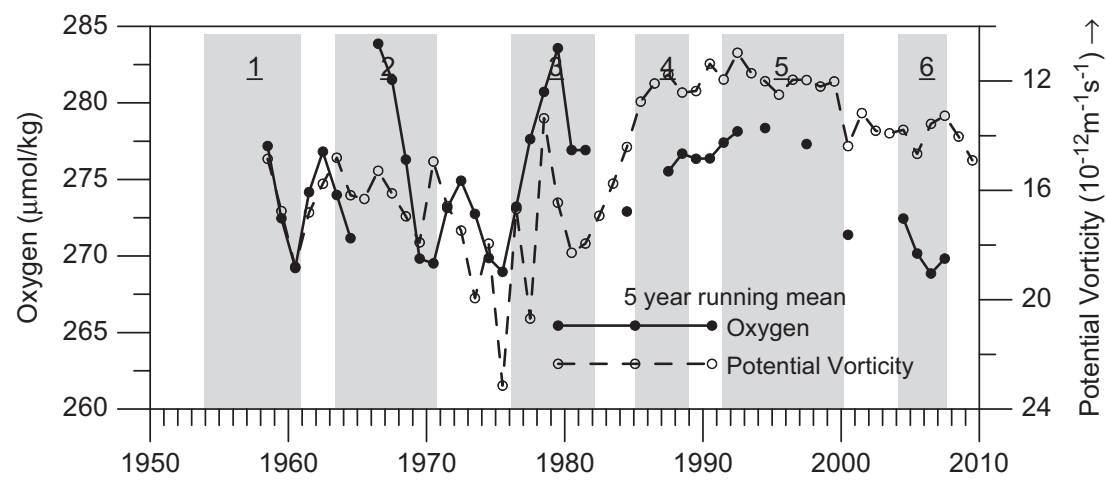

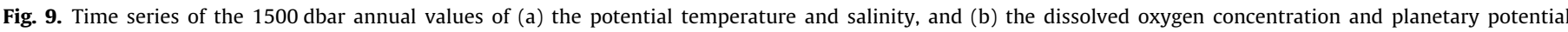

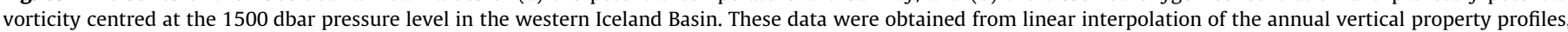
and were subsequently smoothed with a $2 \times 2$ year Bartlett filter to suppress "noise" and fill small gaps (max 2 years) in the time series.

a

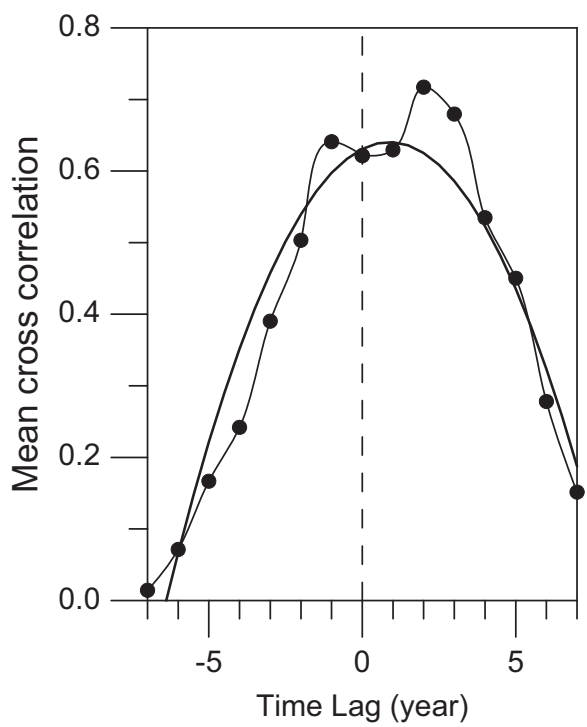

b

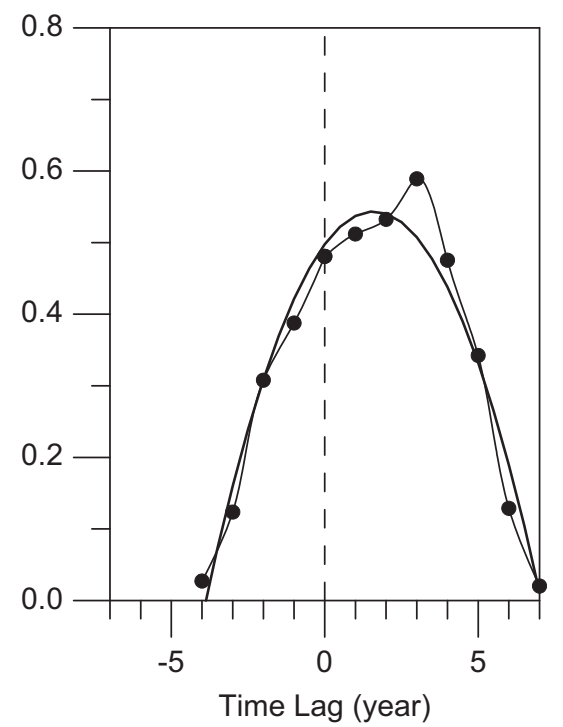

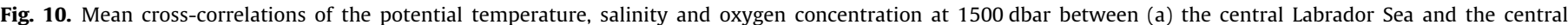

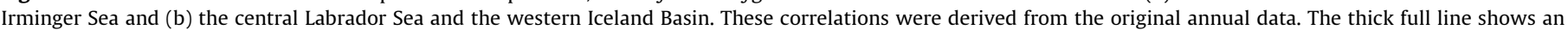
optimal parabolic least squares fit to the positive correlation data.

cross-correlation) (Fig. 10b). Given the stochastic nature of individual correlation estimates, it is likely that the smaller advection times, derived from the asymmetry of the cross-correlation function, based on 12 correlation estimates, are more reliable than the estimate, based on a single correlation maximum.

\section{Heat budget and long-term atmospheric forcing}

In order to determine whether the known meteorologically forced net surface heat flux can explain most of the observed multi-decadal variation of temperature in the intermediate layers, 
we use a primitive heat balance model for the temperature of the intermediate water in the Labrador Sea. The regular occurrence of convective ventilation events is assumed to allow the interior of the intermediate layers to "turbulent" exchange heat with the atmosphere on a more frequent basis than the noted 50-60 year quasi-periodicity of the long-term atmospheric forcing (Fig. 5c). These provisions allow us to regard the central Labrador Sea as a single layer, cooled by the atmosphere, and warmed by inflowing Atlantic currents. The latter advective warming can be interpreted as the throughflow through the Labrador Sea, where relatively warm water enters the basin where it loses its excessive heat to the atmosphere and leaves the same basin at a lower temperature. The inflow from the Irminger Sea by means of the West Greenland Current is assumed to populate relatively shallow levels, while the outflow from the Labrador Sea to the neighbouring basins mainly takes place at intermediate levels via the LSW outflow. Projecting these three-dimensional details on a single line or tube, the main line of heat exchanges in the Labrador Sea can be easily represented by a box model, where we assume that the mean temperature in the upper $2000 \mathrm{~m}, T$, is determined by the net surface heat flux density to the atmosphere $Q_{t o t}$, shown in Fig. $11 \mathrm{a}$, and by a constant integrated advective warming, $Q_{a d v}$.

a

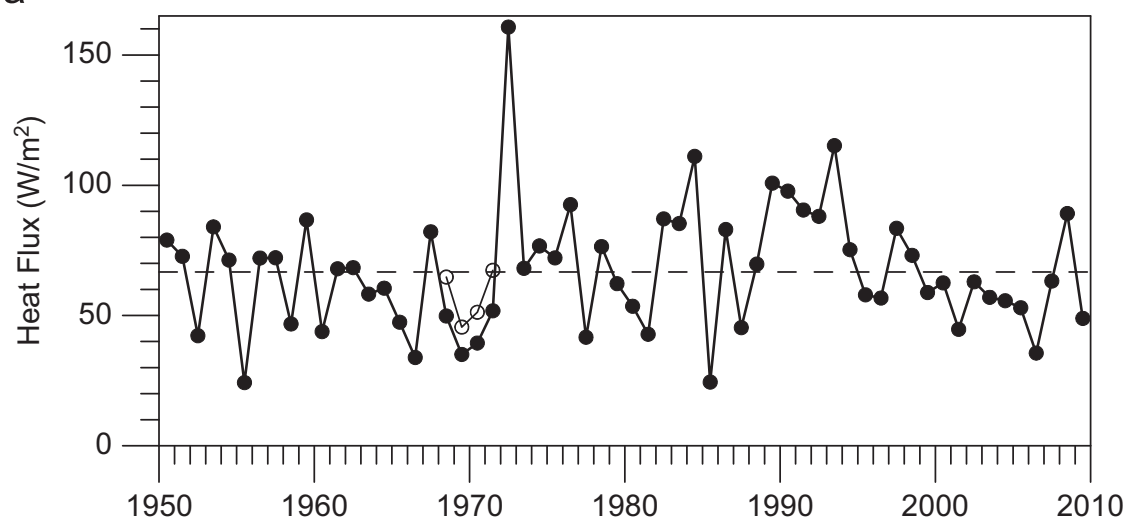

b

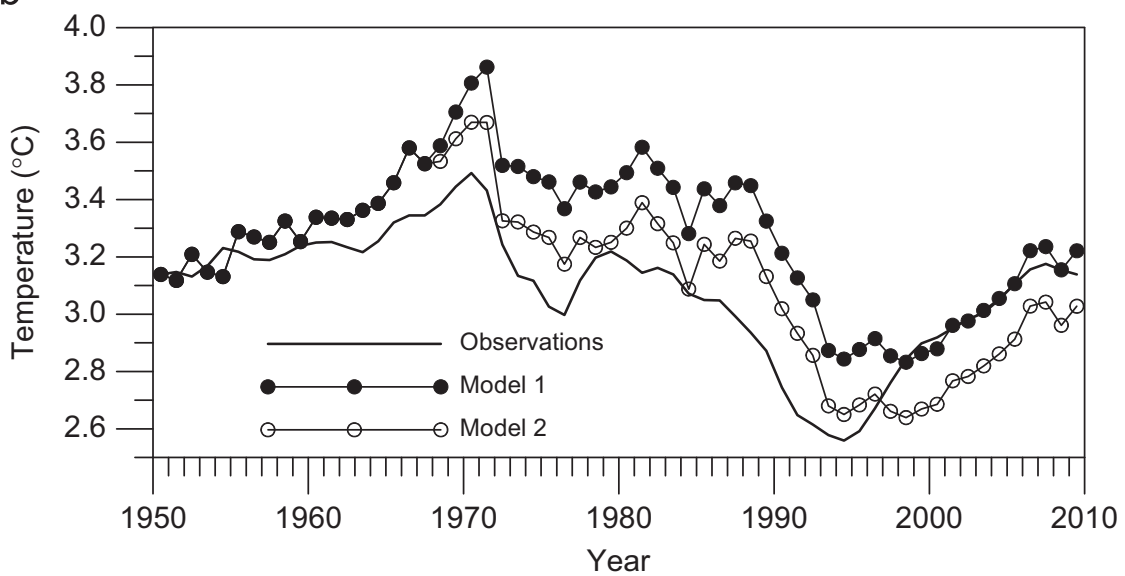

C

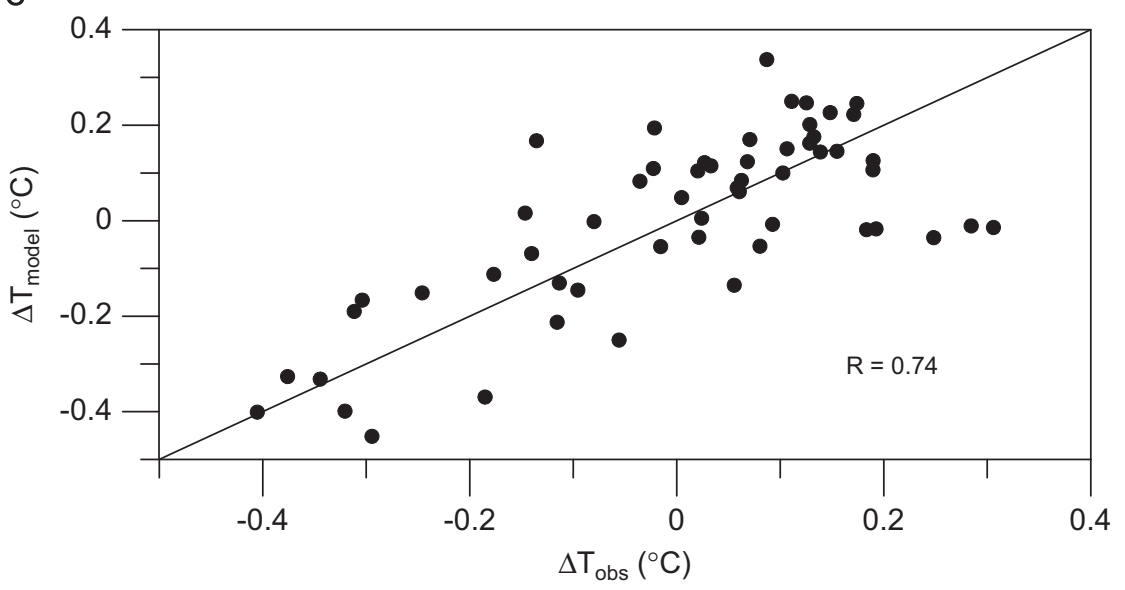

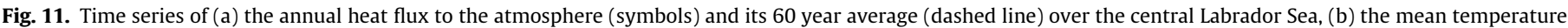

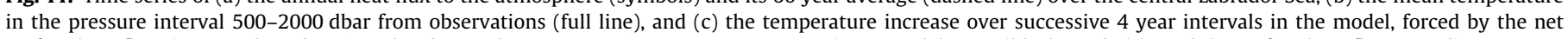

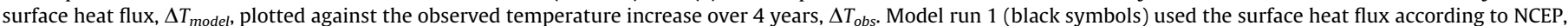
while model run 2 (open symbols) used a 30\% increase in $Q_{t o t}$ for the years 1968-1971. The straight line in (c) shows the identity relation. 
A near-constancy of this advective flux divergence might follow from the heat budget study by Yashayaev and Loder (2009). For the period 2003-2008 their estimated annual advective warming was near constant. Then the development of the temperature can be described as

$H \rho C_{p} \frac{\mathrm{d} T}{\mathrm{~d} t}=-Q_{t o t}+Q_{a d v}$

In this equation $H$ is the layer thickness of $2000 \mathrm{~m}, \rho$ is the water density, and $C_{p}$ is the specific heat. We use the mean potential temperature in the 500-2000 dbar layer as an estimate for the winter temperature in the upper $2000 \mathrm{~m}$ (thick line in Fig. 11b). We have compared our annual temperature with the winter temperature between 1000 and $1500 \mathrm{~m}$, derived from a large number of temperature profiles from Argo floats for the years 2003-2008, published by Yashayaev and Loder (2009). The mean difference amounts to $0.00{ }^{\circ} \mathrm{C}$, with a standard deviation of $0.04{ }^{\circ} \mathrm{C}$, supporting our assumption that the data, derived from hydrographic profiles, are representative for the winter temperature in the Labrador Sea. From the observed net warming between 1950 and 2009 of $0.21{ }^{\circ} \mathrm{C}$ and the long-term mean heat flux density (NCEP/NCAR reanalysis) of $67 \mathrm{~W} / \mathrm{m}^{2}$, the estimate of the mean advective warming $Q_{a d v}$ results in a temperature rise of $0.25^{\circ} \mathrm{C} /$ year. The temperature for 1950 has been used as initial condition. With this approach the results of (2) do not depend on the magnitude of the mean surface heat flux or the mean advective warming since these are assumed to balance each other. Only the variable part of $Q_{\text {tot }}$ will determine the resulting simulated T. Overall, the values for $T$ from the model run 1 (Fig. 11b) follow the multi-decadal variation of the observations (line with black filled symbols in Fig. 11b), with an initial warming period until 1970 , followed by cooling until the lowest temperatures of the $\mathrm{LSW}_{94}$ class were reached, after which a warming trend sets in again. The modelled multi-decadal temperature variations agree in magnitude with the observed variations, indicating that the NCEP/ NCAR heat fluxes perform quite well on that time scale. When we compare the observed annual temperature change with the annual temperature change derived from (2), we find a standard deviation of the difference of $0.09{ }^{\circ} \mathrm{C}$, equivalent with $37 \%$ of the long-term mean heat loss to the atmosphere. The year to year change in the observed temperature correlates significantly with the temperature increase derived from the annual net surface heat flux, $R=0.50$, with the data points evenly distributed around the identity line (Fig. 11c). When determined over an interval of 2 successive years, that correlation $R$ with the 2 year average $Q_{\text {tot }}$ increases to 0.65 , while the correlation of the temperature difference over a 4 year interval with the mean net heat flux over that interval increases to 0.74 (Fig. 11c). This suggests that, apart from a certain noise level, the NCEP/NCAR net surface heat flux variations on shorter time scales are in magnitude also consistent with the observed temperature changes in the central Labrador Sea (Fig. 11a). However, because of the assumed balance between the mean surface heat loss and the constant advective warming, "small" errors in the estimated surface heat flux still can have a lasting influence on the result of a model temperature simulation since they have to be integrated, according to (2). The modelled warming from 1966 until 1971 was considerably larger than in the observations, causing a residual shift between model and observations of the order of $0.2{ }^{\circ} \mathrm{C}$ after 1970 , e.g. for the minimum LSW temperature in 1994 . This can be attributed to either the inadmissibility of our very simple model in the period of the highly stratified Great Salinity Anomaly around 1970, or to an occasional positive bias in the annual mean heat flux to the atmosphere. However, the difference is also influenced by imperfect data on the atmospheric forcing. We can only draw very general conclusions here. This is illustrated by model run 2 that differed from the model 1 run only in heat fluxes $Q_{t o t}$ in the warming years 1968 until
1971. For these 4 years the heat loss to the atmosphere was increased with $30 \%$. This amounts to only about $1.5 \%$ of the longterm total heat loss to the atmosphere for the whole modelling period. The results of model 2 (line with open symbols in Fig. 11b) follow the observations better, and reproduce the temperature minimum in 1994 quite well.

The warming phase of the $\mathrm{LSW}_{94}$ class after 1994 starts faster in reality than in the model, where the warming is delayed, since from 1995 until 1999 the mean net surface heat loss equals within only $1 \%$ the long-term mean value, and surface cooling in the model is in near balance with the advective warming. The observed fast warming may be due to an increased advective warming. In its turn that warming may be caused by the loss of a relatively large volume of LSW to the Irminger Sea, the Iceland Basin, and the Newfoundland Basin (Yashayaev et al., 2007b), compensated by an increased inflow of warmer water. Such increased advective heating, induced by the varying wind stress curl, was also reported by Häkkinen and Rhines (2004) and Hátún et al. (2005). The large volume of the Irminger Basin, occupied by LSW and locally strongly cooled SAMW may also have reduced the temperature gradient in the warm inflow from the Irminger Sea to the Labrador Sea, thereby also reducing the advective heat flux. Apart from the varying wind forcing and temperature gradient, the large volume of high-density $\mathrm{LSW}_{94}$, present in the Labrador Sea, may itself also have induced increased baroclinic flushing of the basin. It appears that an increase in $Q_{a d v}$ for only the 4 years 1995 until 1998 suffices to simulate the observed warming from 1994 until 2009.

Given all the limitations of our extremely simple model and the limited accuracy of the NCEP/NCAR net surface flux estimates, one can conclude that the model forced by these data performs satisfactorily to simulate the overall multi-decadal and decadal form of the temperature curve. Temporal changes in the advective heat input as well as random errors in the NCEP/NCAR heat fluxes are likely to be able to explain most of the differences between the observations and the model.

\section{Discussion}

Studies based on the WOCE and post-WOCE surveys of the AR7 line are mainly dominated by a single particular LSW class, LSW $_{94}$ (e.g. Yashayaev et al., 2007a, 2007b), which shows a simultaneous change in temperature, salinity, dissolved oxygen and potential vorticity. In our study with the extended time series for the Labrador Sea as well as for the Irminger Sea and Iceland Basin, $\mathrm{LSW}_{94}$ still forms the largest, the most homogeneous, and the best oxygenated LSW class since 1950, coinciding with the minimum of the multi-decadal temperature variation (Fig. 3). The extension of our AR7 data, following Yashayaev (2007), has allowed us to demonstrate that the use of additional tracers gives a comprehensive view of the long-term formation history and spreading of LSW classes in the north-western North Atlantic Ocean, different from the history based on the use of temperature and salinity alone. While the temperature and salinity are dominated by a multi-decadal variability, the time series of dissolved oxygen and planetary potential vorticity show near-decadal occurrences of convective ventilation events in the Labrador Sea. This agrees with the analysis of Myers and Donnelly (2008) who also found a near-decadal occurrence of strong formation events of LSW, derived from the NCEP/NCAR surface fluxes.

Talley and McCartney (1982) already noted in 1982 that potential vorticity is a powerful tracer for the study of LSW spreading. This was reconfirmed by Yashayaev et al. (2007a), who used the related thickness of density layers to identify the dominant LSW class. In some recent studies also man-made 
chemical tracers like different types of chlorofluorocarbon (CFC) have been used to study the formation and spreading of LSW (e.g. Azetsu-Scott et al., 2003; Kieke et al., 2006, 2007). However, high-quality CFC data are not available with an annual resolution in the Irminger and Iceland basins, only in the AR7W surveys in the Labrador Sea (Azetsu-Scott et al., 2003).

Observation of potential temperature mainly shows a multidecadal quasi-oscillation with a characteristic time scale of about 50 years (comparable with the duration of reliable data coverage), and a magnitude of about $0.75^{\circ} \mathrm{C}$, while the salinity shows multidecadal as well as decadal variations with a total range of nearly 0.1 (Fig. 5a). A harmonic analysis of the temperature and salinity with a period of 50 years explains $69 \%$ of the temperature variance at $1500 \mathrm{dbar}$ and $63 \%$ of the salinity variance. The convective ventilation, or LSW formation events, derived from the time series of dissolved oxygen and potential vorticity has a much smaller characteristic time scale of about 10 years (Figs. 4 and $5 \mathrm{~b}$ ). On that time scale the mean related magnitude of the temperature variation is of the order of $0.1-0.2{ }^{\circ} \mathrm{C}$. The related salinity changes at 1500 dbar do not show a generic form or sign. Probably the varying surface salinities, reflecting the complex interplay of different freshwater sources, are responsible for this phenomenon. The LSW class associated with event 3, formed after the Great Salinity Anomaly in the mid-1970s, as well as the LSW $_{94}$ class in the early 1990s (5) are relatively fresh, while the LSW classes formed in the 1950 s and the 1960 s are relatively saline (Fig. 5a).

The simple heat balance model, introduced above, does not simulate LSW formation explicitly via convective ventilation events; it only simulates the total heat budget of the intermediate layers in the central Labrador Sea. However, since the year to year annual mean heat fluxes were used in the model run, it certainly also contains such events. An example is the LSW formation in the mid-1970s, initiated by strong heat fluxes in 1973 after the end of Great Salinity Anomaly (Fig. 11a). This resulted in a relatively fresh LSW class (event 3 ), characterised by a relatively low temperature $\left(0.3^{\circ} \mathrm{C}\right.$ lower $)$, compared to the multi-decadal temperature change (Fig. 5a). The formation of the $\mathrm{LSW}_{94}$ class, with its maximum expression in the Labrador Sea in 1994 (event 5), followed several years of strong heat loss (1989 until 1994), about $40 \%$ above the long-term mean surface heat flux (Fig. 11a). This strong increase in $Q_{\text {tot }}$ allowed a considerable cooling after 6 successive cold winters (Lazier et al., 2002), and enabled by the relatively long thermal "memory" of the Labrador Sea. Comparison of the observed temperature changes in the intermediate layers of the Labrador Sea (500-2000 dbar) with the temperature changes, derived from the NCEP/NCAR reanalysis net heat flux by means of (2) (Fig. 11c), indicates that the reanalysis net heat flux has the correct magnitude, despite the criticisms on this product referred above. Våge et al. (2009) have suggested that in some cases the influence of the severity of the winters is necessary, but chance also may play an important role in the occurrence of convective ventilation events, e.g. the location of the ice edge in winter relative to the convection centre.

According to Straneo et al. (2003), part of the LSW formed in the Labrador Sea flows into the Irminger Sea along a direct recirculation between both ocean basins. From the analysis of PALACE float tracks and an advection-diffusion model, they found that it takes over 1 year for any significant amount of LSW to reach the Irminger Sea, and about 2 years for newly formed LSW to fill the centre of that basin. This agrees with the transit time estimates for $\mathrm{LSW}_{94}$ and $\mathrm{LSW}_{2000}$ by Yashayaev et al. (2007a). Our data from the Irminger Sea (temperature, salinity, dissolved oxygen, and potential vorticity) show, with a 1 (asymmetry of parabolic fit) to 2 year (maximum cross-correlation) delay, a similar temporal structure as that from the Labrador Sea, and confirm the idea of advection of LSW from its formation region into the Irminger Basin. Our transit time estimate, based on the cross-correlation of the 60 year time series of salinity, temperature, and dissolved oxygen (Fig. 10a) agrees with the estimates by Straneo et al. (2003) and Yashayaev et al. (2007a, 2007b). Apparently the advective transport velocity of LSW to the Irminger Sea does not seem to vary strongly with the gyre forcing by the wind stress curl. However we have to consider that we have only a very small number of independent estimates of the advective time scales. We note also that we have used the assumption that temperature, salinity, and oxygen concentration are not seriously affected by local convection in the Irminger Sea on the time scales involved. Our correlation analysis is based on 60 year time series, while deep local convection reaching as deep as $1500 \mathrm{dbar}$ in the Irminger Sea is at best a rare episodic phenomenon (de Jong, 2010). Therefore it is unlikely to strongly influence our results.

Talley and McCartney (1982) already have shown that LSW not only leaves the Labrador Sea through a western boundary current towards the Newfoundland Basin, and via the sub-arctic gyre circulation towards the Irminger Sea, it can also spread eastward and reach the Iceland Basin and basins further east, advected in the lower parts of the North Atlantic Current near $50^{\circ} \mathrm{N}$. They found a minimum in planetary vorticity in the Iceland Basin at a comparable potential density $\sigma_{1.5}=37.70-37.72$ according to Knudsen's equation of state, which agrees with $\gamma_{1.5}=34.675-$ $34.695 \mathrm{~kg} / \mathrm{m}^{3}$, according to the 1980 equation of state for sea water. The LSW core in the Iceland Basin interleaves between the warmer and more saline thermocline water and the underlying more saline ISOW. The overall temporal variation in temperature and salinity of the LSW in the Iceland Basin at $1500 \mathrm{dbar}$, dominated by a multi-decadal oscillation, is similar to the temporal structure of LSW in the Labrador Sea. In the time series of dissolved oxygen and planetary potential vorticity from the Iceland Basin, several peaks, related to the convective ventilation events in the Labrador Sea, can be recognised. An estimate of the time lag between both basins, again based on the asymmetry and the maximum of the crosscorrelation of these parameters, amounts to 1.5-3 year faster than the estimates for individual LSW classes by Yashayaev et al. (2007a) of 5 years for $\mathrm{LSW}_{94}$ and 4 years for $\mathrm{LSW}_{2000}$. The advection we find is more similar to the eastward LSW advection, proposed by Sy et al. (1997); according to them it takes only 2-3.5 years to the Iceland Basin.

In the comparison of our transit times with those from literature we have to realise that all other authors have used some form of feature tracking to estimate the advection velocity of single LSW events. Our estimates are based on the analysis of long time series of temperature, salinity, and oxygen concentration, presenting not only a series of 6 or 7 LSW events at 1500 dbar, but also the non-LSW events in between. The feature tracking studies mainly focus on the spreading velocity of 1-3 LSW events. Moreover, the extremely large volume of $\mathrm{LSW}_{94}$ itself may have influenced its characteristic advection velocity, according to Straneo (2006). Apart from that, the wind driven cyclonic gyre circulation in the north-western North Atlantic will also show inter-annual to multi-decadal variability, given the strong multi-decadal variability of the wind stress curl over the Labrador Sea, as shown in Fig. 5c. Such a variation in the forcing will certainly lead to a variation of advection estimates, based on the tracking of individual features. What we have determined is the average transit time for hydrographic features at the $1500 \mathrm{dbar}$ level, which seems to be faster than most transit times, derived from the tracking of single hydrographic features. The apparent systematic difference between both methods to estimate transit times deserves a further analysis, e.g. by comparison of model results. 
The results, presented here, reconfirm that considerable parts of the LSW classes, produced by air-sea interaction in the Labrador Sea, do not flow directly south in a deep western boundary current but move from their source region to the east (Iceland Basin) and northeast (Irminger Sea). LSW classes can even reach the European ocean margin (Talley and McCartney, 1982; van Aken, 2000; Yashayaev et al., 2007a, 2007b). This supports the ideas, expressed by Bower et al. (2009), that interior pathways of the cold branch of the AMOC may be at least as important as the deep western boundary current.

Overall one can summarise that the long-term variations of the salinity and potential temperature at intermediate depths in the northern North Atlantic Ocean mainly reflect the multi-decadal variation of the meteorological forcing of the Labrador Sea, in particular of the surface heat loss to the atmosphere. Using water mass tracers like dissolved oxygen and the planetary potential vorticity it has been shown that individual convective ventilation events that reach a pressure of over 1500 dbar and produce deep LSW classes have occurred about once in every 10 years in the last six decades. The analysed parameters, especially the potential vorticity, suggest that shallower LSW classes are produced more often. By advection, which takes on average only a few years, the newly formed LSW classes at 1500 dbar reach the neighbouring ocean basins quite fast (Irminger Sea, $\sim 1-2$ years; Iceland Basin 1.5-3 years), feeding the interior pathways of the AMOC (Bower et al., 2009; Lozier, 2010).

\section{Acknowledgements}

The research by HMvA and MFdJ leading to these results has received funding from the European Community's 7th framework programme (FP7/2007-2013) under Grant agreement no. GA212643 (THOR: "Thermohaline Overturning - at Risk", 2008-2012), and from the Dutch Climate for Spatial Planning programme CS1.

The pre-1990 hydrographic data were obtained from the NOAA World Ocean Data Base and ICES oceanographic data base, Data from the AR7E section from the WOCE Hydrographic Program Office and from the ocean research and monitoring programs run by our and partnering institutions. Non-public data from this section were obtained via Detlef Quadfasel and Manfred Bersch. The atmospheric forcing data were obtained from NOAA and the University of East Anglia. We thank the generations of oceanographers and technicians, who collected these data, as well as the data managers, who took care of them, for their efforts, which enabled this research.

We also acknowledge the efforts by three anonymous reviewers, who significantly contributed to an improvement of the original article.

\section{References}

Azetsu-Scott, K., Jones, E.P., Yashayaev, I., Gershey, R.M., 2003. Time series study of CFC-concentrations in the Labrador Sea during deep and shallow convection regimes (1991-2000). Journal of Geophysical Research 108, 3354. doi:10. 1029/202JC001317.

Bacon, S., Gould, W.J., Jia, Y., 2003. Open-ocean convection in the Irminger Sea. Geophysical Research Letters 30, 1246. doi:10.1029/2002GL016271.

Bendat, J.S., Piersol, A.G., 1986. Random Data 2nd ed. Wiley Interscience, New York, p. 566.

Boessenkool, K.P., Hall, I.R., Elderfield, H., Yashayaev, I., 2007. North Atlantic climate and deep-ocean flow speed changes during the last 230 years. Geophysical Research Letters 34, L13614. doi:10.1029/2007GL030285.

Bower, A.S., Lozier, S., Gary, S.F., Böning, C.W., 2009. Interior pathways of the North Atlantic Meridional overturning circulation. Nature 459, 243-247. doi:10. 1038/nature-7979.

Brambilla, E., Talley, L.D., 2008. Subpolar mode water in the norteastern Atlantic: 1. Averaged properties and mean circulation. Journal of Geophysical Research 113, C04025. doi:10.1029/2006JC004062.

Centurioni, L.R., Gould, W.J., 2004. Winter conditions in the Irminger Sea observed with profiling floats. Journal of Marine Research 62, 226-313.
Clarke, R.A., Gascard, J.-C., 1983. The formation of Labrador Sea Water. Part I: Large-scale processes. Journal of Physical Oceanography 13, 1764-1778.

Curry, R.G., McCartney, M.S., Joyce, T.M., 1998. Oceanic transport of subpolar climate signals to mid-depth subtropical waters. Nature 391, 575-577.

de Jong, M.F., 2010. Hydrographic variability of the Irminger Sea, PhD thesis, Utrecht University, Utrecht, p. 208.

Dickson, R.R., Meincke, J., Malmberg, S.-A., Lee, A.J., 1988. The Great Salinity anomaly in the northern North Atlantic 1968-1982. Progress in Oceanography 20, 103-151.

Dietrich, G., 1975. Allgemeine Meereskunde: eine Einführung in die Ozeanographie. 3-rd print Borntraeger, Berlin, p. 593.

Emery, W.J., Meincke, J., 1986. Global water masses - summary and review. Oceanologica Acta 9, 383-391.

Falina, A., Sarafanov, A., Sokov, A., 2007. Variability and renewal of Labrador Sea Water in the Irminger Basin in 1991-2004. Journal of Geophysical Research 112, C01006. doi:10.1029/2005JC003348.

Fischer, J., Schott, F.A., Dengler, M., 2004. Boundary circulation at the exit of the Labrador Sea. Journal of Physical Oceanography 34, 1548-1570.

Gascard, J.C., Clarke, R.A., 1983. The formation of Labrador Sea Water. Part II: Mesoscale and smaller-scale processes. Journal of Physical Oceanography 13 , 1779-1797.

Gill, A.E., 1982. Atmosphere-Ocean Dynamics, International Geophysics Series, 30. Academic Press, New York, p. 662.

Häkkinen, S., Rhines, P.B., 2004. Decline of subpolar Atlantic circulation during the 1990s. Science 304, 555-559.

Hátún, H., Sandø, A.B., Drange, H., Hansen, B., Valdimarson, H., 2005. Influence of the Atlantic subpolar gyre on the thermohaline circulation. Science 3009 , 1844-1942.

Katsman, C.A., Spall, M.A., Pickart, R.S., 2004. Boundary current eddies and their role in the restratification of the Labrador Sea. Journal of Physical Oceanography 34, 1967-1983.

Kieke, D., Rhein, M., Stramma, L., Zenk, W., 2006. Changes in the CFC inventrories and formation rates of Upper Labrador Sea Water, 1997-2001. Journal of Physical Oceanography 36, 64-86.

Kieke, D., Rhein, M., Stramma, L., Smethie, W.M., Bulliter, J.L., LeBel, D.A., 2007. Changes in the pool of Labrador Sea Water in the subpolar North Atlantic Geophysical Research Letters 34, L06605. doi:10.1029/2006GL028959.

Kistler, R., Kalnay, E., Collins, W., Saha, S., White, G., Woollen, J., Chelliah, M., Ebisuzaki, W., Kanamitsu, M., Kousky, V., van den Dool, H., Jenne, R., Fiorino, M., 2001. the NCEP-NCAR 50 year reanalysis: monthly means CD-ROM and documentation. Bulletin of the American Meteorological Society 82, 247-268.

Lazier, J.R.N., 1980. Oceanographic conditions at O.W.S. Bravo 1964-1974. Atmospheres and Oceans 18, 227-238.

Lazier, J., Hendry, R., Clarke, A., Yashayaev, I., Rhines, P., 2002. Convection and restratifition in the Labrador Sea, 1990-2000. Deep-Sea Research I 49, 1819-1835.

Lozier, M.S., 2010. Deconstructing the conveyor belt. Science 328, 1507-1511. doi:10.1126/science. 1189250.

McCartney, M.S., Talley, L.D., 1982. The subpolar mode water of the North Atlantic Ocean. Journal of Physical Oceanography 12, 1169-1188.

McCartney, M.S., Talley, L.D., 1984. Warm-to-cold water conversion in the northern North-Atlantic ocean. Journal of Physical Oceanography 14, 922-935.

Myers, P.G., Donnelly, C., 2008. Water mass transformation and formation in the Labrador Sea. Journal of Climate 21, 1622-1638. doi:10.1175/2007JCL1722.1.

Pickart, R.S., Straneo, F., Moore, G.W.K., 2003. Is Labrador Sea Water formed in the Irminger Basin? Deep-Sea Research I 50, 23-52.

Rahmstorf, S., 1995. Bifurcation of the Atlantic thermohaline circulation in response to changes in the hydrological cycle. Nature 378, 145-149.

Renfrew, I.A., Moore, G.W.K., Guest, P.S., Bumke, K., 2002. A comparison of surface layer turbulent flux observations over the Labrador Sea with ECMWF analyses and NCEP reanalyses. Journal of Physical Oceanography 32, 383-400.

Rhein, M., Kieke, D., Steinfeldt, R., 2007. Ventilation of the Upper Labrador Sea Water, 2003-2005. Geophysical Research Letters 34, L06603. doi:10.1029| 2006 GL028540.

Sarafanov, A., 2009. On the effect of the North Atlantic oscillation on temperature and salinity of the subpolar North Atlantic intermediate and deep waters. ICES Journal of Marine Science 66 (7), 1448-1454. doi:10.1093/icesjms/fsp094.

Stein, M.L., 1999. Interpolation of Spatial Data. Springer Verlag Inc., New York 257 p.

Steinfeldt, R., Tanhua, T., Bullister, J.L., Key, R.M., Rhein, M., Kohler, J., 2010. Atlantic CFC-data in CARINA. Earth System Science Data 2, 1-15.

Stenardo, I., Gruber, N., Körtzinger, A., 2009. CARINA oxygen data in the Atlantic Ocean. Earth System Science Data 1, 87-100.

Straneo, F., 2006. Heat and freshwater transport through the central Labrador Sea. Journal of Physical Oceanography 36, 606-628.

Straneo, F., Pickart, R.S., Lavender, K., 2003. Spreading of Labrador sea water: an advective-diffusive study based on Lagrangian data. Deep-Sea Research I 50 701-719.

Sy, A., Rhein, M., Lazier, J.R.,.N., Koltermann, K.P., Meincke, J., Putzka, A., Bersch, M. 1997. Surprisingly rapid spreading of newly formed intermediate waters across the North Atlantic Ocean. Nature 386, 675-679.

Talley, L.D., McCartney, M.S., 1982. Distribution and circulation of Labrador Sea Water. Journal of Physical Oceanography 12, 1189-1205.

Tanhua, T., Steinfeldt, R., Key, R.M., Brown, P., Gruber, N., Wanninkhof, R., Perez, F., Körtzinger, A., Velo, A., Schuster, U., van Heuven, S., Bullister, J.L., Stendaro, I., hoppema, M., Olsen, A., Kozyr, A., Pierrot, D., Schirnick, C., Wallace, D.W.R. 2010. Atlantic Ocean CARINA data: overview and salinity adjustment. Earth System Science Data 2, 17-34. 
Tomczak, M., 1999. Some historical, theoretical and applied aspects of quantitative water mass analysis. Journal of Marine Research 57, 275-303.

Uppala, S.M., Kållberg, P.W., Simmons, A.J., Andae, U., da Costa Bechtold, V. Fiorino, M., Gibson, J.K., Haseler, J., Hernandez, A., Kelly, G.A., Li, X., Onogi, K., Saarinen, S., Sokka, N., Allen, R.P., Andersson, E., Arpe, K., Balmaseda, M.A. Beljaars, A.C.M., van de Berg, L., Bidlot, J., Bormann, N., Caires, S., Chevallier, F., Dethof, A., Dragosavac, M., Fisher, M., Fuentes, M., Hagemann, S., Hólm, E. Hoskins, B.J., Isaksen, L., Janssen, P.A.E.M., Jenne, R., McNally, A.P., Mahfouf, J.-F., Moncrette, J.J., Rayner, N.A., Saunders, R.W., Simon, P., Sterl, A. Trenberth, K.E., Untch, A., Vasiljevic, D., Viterbo, P., Woollen, J., 2005. The ERA-40 reanalysis. Quarterly Journal of the Royal Meteorological Society 131, 2961-3012.

Våge, K., Pickart, R.S., Thierry, V., Reverdin, G., Lee, C.M., Petrie, B., Agnew, T.A., Wong, A., Ribergaard, M.H., 2009. Surprising return of deep convection to the subpolar North Atlantic Ocean in winter 2007-2008. Nature Geoscience 2, 67-72. doi:10.1038/NGEO382.

Våge, Pickart, K.R.S., Sarafanov, A., Knutsen, Ø., Mercier, H., Lherminier, P., van Aken, H.M., meincke, J., Quadfasel, D. The Irminger gyre, circulation, convection, and interannual variability. Submitted to Deep-Sea Research I, unpublished manuscript.

van Aken, H.M., 2000. The hydrography of the mid-latitude Northeast Atlantic Ocean: II, The intermediate water masses. Deep-Sea Research I 47, 789-824. van Aken, H.M., de Boer, C.J., 1995. On the synoptic hydrography of intermediate and deep water masses in the Iceland Basin. Deep-Sea Research 42, 165-189.

van Aken, H.M., Becker, G., 1996. Hydrography and through-flow in the northeastern North Atlantic Ocean: the NANSEN project. Progress in Oceanography 38, 297-346.

Yashayaev, I., 2007. Hydrographic changes in the Labrador Sea, 1960-2005. Progress in Oceanography 73, 242-276.

Yashayaev, I., Bersch, M., van Aken, H.M., 2007a. Spreading of the Labrador Sea Water to the Irminger and Iceland Basins. Geophysical Research Letters 34, L10602. doi:10.1029/2006GL028999.

Yashayaev, I., van Aken, H.M., Holliday, P., Bersch, M., 2007b. Transformation of the Labrador Sea Water in the subpolar North Atlantic. Geophysical Research Letters 34, L22605. doi:10.1029/2007GL031812.

Yashayaev, I., Dickson, B., 2008. Transformation and fate of overflows in the northern North Atlantic. In: Dickson, R.R., Meincke, J., Rhines, P. (Eds.), ArcticSubarctic Ocean Fluxes. Defining the Role of the Northern Seas in Climate. Springer, Dordrecht, The Netherlands, pp. 505-526.

Yashayaev, I., Loder, J.W., 2009. Enhanced production of Labrador Sea Water in 2008. Geophysical Research Letters 36, L01606. doi:10.1029/2008GL036162.

Yu, L. Weller, R.A., 2007. Objectively analyzed air-sea het fluxes for the global icefree oceans (1981-2005). Bulletin of the American Meteorological Society, 133. doi:10/1175/BAMS-88-4-527. 